\title{
Pharmacologic Management of Aggression in Adults with Intellectual Disability
}

\author{
Durga Roy ${ }^{1 *}$, Pamela Hoffman ${ }^{2}$, Melissa Dudas ${ }^{3}$ and Alan Mendelowitz ${ }^{2}$
}

${ }^{1}$ Johns Hopkins University School of Medicine, Baltimore, MD

${ }^{2}$ Hofstra Northshore Long Island Jewish Health System, New Hyde Park, NY

${ }^{3}$ Mount Sinai School of Medicine, NY, NY

\begin{abstract}
Introduction: Aggression is a common behavioral problem seen in patients with intellectual disabilities (ID). The safety and efficacy of second generation antipsychotics (SGAs), mood stabilizers and antidepressants in the management of aggression in these individuals have minimally been studied. This review aims to 1) summarize the studies conducted using second generation antipsychotics, mood stabilizers and antidepressants in treating aggressive behaviors in patient with ID and 2) determine based on the existing literature, which medications have been examined in the most rigorous study design that might suggest the most efficacy for use in clinical practice.

Methods: Literature searches using PUBMED Central, CINAHL Plus, PsychINFO, and Embase databases were conducted using the following terms: intellectual disability/disabilities, mental retardation, developmental disability/disabilities, aggression, agitation, behavior disorder, adult, treatment, management. Studies predominantly including children with ID, and autism/pervasive developmental disabilities spectrum disorders were excluded. Analyses were done by class of medication: SGAs, mood stabilizers and antidepressants. The primary outcome measure was reduction in aggressive or self injurious behaviors as measured by each individual study.

Results: The most rigorous study designs found using these agents were randomized controlled trials (RCT). A total of 10 RCTs were found, the majority being with risperidone (3) and lithium (2). Treatment with risperidone showed reduction in aggression when compared to placebo in most RCTs with the exception of one study in which risperidone was not better than placebo. Both lithium studies showed reduction in aggression when compared to placebo. The most abundant literature exists in retrospective chart reviews. The most commonly studied agent was risperidone which showed reduction in aggression in majority of the studies.

Conclusions: Limited data exists for treatment of aggression in adults with ID. There are very few studies examining pharmacologic agents using RCTs. Given that risperidone and lithium were the most commonly studied agents in the most rigorous experimental design, it is suggested that these two agents prove efficacious for treatment of aggression in patients with ID. Limitations to most of these studies included concomitant psychotropic administration with variations in types and dosing, severity of ID, and the idea that a wide variety of aggression scales were used to assess outcome. Further research with more scientific rigor is required in this field.
\end{abstract}

Keywords: intellectual disability, mental retardation, treatment.

\section{INTRODUCTION}

Aggression is a common behavioral problem seen in individuals with intellectual disability (IDD). Aggression is socially inappropriate physical or verbal behavior that can be directed either towards another individual, object or the self. Aggressive behaviors may be observed within the spectrum of agitation [1]. Aggression is often the primary reason that individuals are admitted or readmitted to institutional settings [2] and appears to be the primary reason why persons with intellectual disabilities are placed on psychotropic or behavioral control medications [3].

Behaviors including property destruction, physical aggression towards others and self injurious behaviors are commonly observed among IDD. This cluster of

*Address correspondence to this author at the Johns Hopkins University School of Medicine, 5300 Alpha Commons Drive, Baltimore, MD 21224, USA; Tel: 410-550-9616; Fax: 4105508191; E-mail: droy4@jhmi.edu target symptoms has become defined as "challenging behaviors" [4]. These target symptoms exist in high rates among this patient population. The point prevalence for aggressive behaviors towards others or objects, using the Diagnostic Criteria for Psychiatric Disorders for Use with Adults with Learning Disabilities/ID (Royal College of Psychiatrists 2001), was reported to be $9.8 \%$ and $4.9 \%$ for self-injurious behaviors [5]. A study conducted in two areas of England determined that such behaviors are shown by $10-15 \%$ of people with intellectual disability who are in contact with educational, health or social care services for such individuals. According to Cooper, the most common forms of challenging behaviors reported are aggression $(7 \%)$, destructive behavior $(4 \%-5 \%)$ and self-injury (4\%) [5]. The study also revealed that the majority of people identified showed two or more of these four general forms of challenging behavior and approximately two-thirds of the people identified were boys/men. Of those, two-thirds of the people identified were adolescents or young adults. Approximately $50 \%$ 
of people identified as demonstrating challenging behavior were living with their families and were more likely to need greater levels of assistance in eating, dressing and washing, be incontinent and have more restricted expressive and receptive communication [6].

The cause of aggression in IDD can be difficult to ascertain as often, these individuals have limited communication skills, which results in ambiguity of symptoms and behaviors. This often leads to an unclear diagnosis or even misdiagnosis. A thorough examination of the differential diagnosis of aggression must be assessed, and can be divided into 3 major categories: psychiatric, medical and environmental. In considering the differential diagnosis of the aggression, the severity of ID as well and other medical and psychiatric comorbidities must be considered. Psychiatric causes of aggression include psychosis, anxiety, mood symptoms, frontal lobe dysfunction, as well psychopathology evidenced by personality disorders [7-10]. Medical causes might include fecal impaction, pain, seizure disorder with post-ictal confusion, delirium, and new onset dementia (typically seen in profound mental retardation such as Down's Syndrome) [11]. latrogenic medical sources include disinhibition with benzodiazepines/steroids, druginduced akathisia, or alcohol/illicit drug intoxication (seen mostly with patients with mild ID) [12-14]. Common causes for aggression in this population may include environmental triggers such as changes in staff in the residence, a new roommate, or interpersonal conflicts. Abuse and neglect are also present in the environmental settings of many of these individuals that might cause aggressive behaviors [15].

Given the complexity of determining the etiology of aggression in this population, it is difficult to treat aggressive behaviors in these individuals who very often require close monitoring and supervision in clinical settings. Though behavioral interventions are often most effective, pharmacologic interventions are required to target the three common core challenging behaviors of property destruction, physical aggression and self injury.

Several reviews have examined the utility of pharmacotherapy focused on treating adults with ID and these behaviors [16-20]. A study in Norway determined that many as $37 \%$ of people with administratively defined mental retardation were prescribed psychotropic medication. Antipsychotics were the most widely used, followed by antidepressants and anticonvulsants [21]. It is well documented that first generation antipsychotics have been used to treat acute aggression in this patient population, however clinical evidence supports that patients with ID are more susceptible to developing extrapyramidal side effects, particularly akathisia and tardive dyskinesia [22].

One of the main challenges with treatment of aggressive behaviors in individuals with ID with psychotropics is polypharmacy. It has been extensively documented that individuals with ID are very likely to be prescribed several psychotropics concomitantly [23]. Spreat, Conroy, and Jones calculated that psychotropic drug use in the Oklahoma ID system was $22.4 \%$ of all persons with ID [24]. More recent data show similar rates of psychotropic drug use with a shift to second generation antipsychotics and selective serotonin reuptake inhibitors (SSRIs) [25]. Understanding how much scientific rigor is used to experimentally study these agents is important in justifying why and how we use these agents to treat aggression in patients with ID.

Given that antipsychotics, mood stabilizers and antidepressants are the most commonly prescribed medications to treat aggressive behaviors in this population, it is critical to review the studies examining the safety and efficacy of these medications. This paper comprehensively examines the existing literature on use of second generation antipsychotics, mood stabilizers and antidepressants in the management of aggression in patients with ID on a spectrum from most to least rigorous experimental design. This review has two aims: 1) to summarize the studies conducted using second generation antipsychotics, mood stabilizers and antidepressants in treating aggressive behaviors in IDD 2) to determine, based on the existing literature, which medications have been examined in the most rigorous study design that might suggest the most efficacy for use in clinical practice.

\section{METHODS}

An English language literature search was conducted through PUBMED Central, CINAHL Plus, PsychINFO, and Embase databases for articles dating from 1980 to 2013. The search was conducted using the following keywords: intellectual disability/disabilities, mental retardation, developmental disability/disabilities, aggression, agitation, behavior disorder, adult, treatment, management. 


\section{Inclusion Criteria}

All experimental designs were included. Adult subjects with an Axis II diagnosis of any severity of mental retardation or intellectual disability were included. Adult was defined as any individual above the age of 16 . Only studies that targeted aggression (any severity of aggression noted) using a second generation antipsychotic, mood stabilizer or antidepressant were included. To identify additional studies, a hand-search of the reference lists of those studies included in other systematic reviews was included.

\section{Exclusion Criteria}

Given that many medications for aggression are not approved for use in children, children under the age of 16 were excluded for any study that had more than $50 \%$ of subjects under age 16 . While overlap of ID with autism spectrum and pervasive developmental disorder occurs, it results in a heterogeneous study of children and adults and these disorders were not the focus of this paper. Therefore, studies with more than $50 \%$ subjects carrying a diagnosis of autism spectrum/ pervasive developmental disabilities disorders were excluded from this analysis. Studies targeting symptoms of mood disorders or psychotic disorders were excluded. Any articles for which full text was unavailable were excluded.

The primary outcome measure was reduction in aggressive or self-injurious behaviors as measured by each individual study. A $p$ value $<0.05$ was considered significant in each study when available.

\section{RESULTS}

Results are presented below organized as follows: 1) trial design 2) drug class 3 ) order of most reported studies to the least reported studies. The most commonly used aggression scales found in the studies are summarized in Appendix 1. In total, 42 studies met the criteria described above and are detailed below.

\section{Randomized Controlled Trials}

A total of 10 randomized controlled trials using a double blind placebo controlled design were found using second generation antipsychotics (6), mood stabilizers (3) and antidepressants (1), and are summarized in Table 1.

\section{Second Generation Antipsychotics}

Of the 6 randomized double blind placebo controlled trials using second generation antipsychotics, 3 of these compared risperidone to placebo [26-28]. Only Tyrer's study compared haloperidol to risperidone and placebo, showing that aggressive behavior in subjects given placebo showed no evidence at any time points of worse response than did patients assigned to either of the antipsychotic drugs. These results were not statistically significant (combined $p=0.06$ ) [26]. In each arm, the most common severity of ID was moderate. In contrast, two studies showed that risperidone yielded significant reduction in aggression compared to placebo based on $\mathrm{ABC}, \mathrm{BPI}$ and $\mathrm{CGI}$ scores $[27,28]$. Though some subjects dropped out due to sedation [28], and subjects were also on existing medications, both studies yielded statistically significant results $(P$ $<0.05$ ).

Both risperidone and olanzapine showed reduction in aggression in a single blind study, however risperidone had a higher efficacy index than olanzapine and the results showed a statistically significant reduction towards self injury [29].

Clozapine has only been studied twice in controlled clinical trials, by Hammock. In a single blind study of two subjects, clozapine [30] showed significant reduction in self injurious behaviors and downward trend on $4 \mathrm{ABC}$ subscales when randomized to dosage baseline. One subject had previously been in a double blind placebo controlled crossover trial in which his self injurious behavior was reduced from 148 per hour to 24 per hour at $225 \mathrm{mg}$ of clozapine [31]. Since he had a seizure at $300 \mathrm{mg}$ of clozapine, his dose had been reduced and valproic acid had been added. This combination resulted in lethargy and he was switched to risperidone without success.

\section{Mood Stabilizers}

Three studies have been conducted using lithium in a randomized control trial. A total of 2 studies were found comparing lithium to placebo [32, 33]. Craft's study used the Dale score $(1=$ well behaved; $2=\operatorname{mood}$ uncertain; $3=$ overt aggression or attempted aggression; $4=$ additional medication required to control patient; $5=$ seclusion required) to measure reduction in symptoms but did not define specific target symptoms. Compared to placebo, subjects on lithium showed reduction in scores, $\mathrm{P}=0.002$ [32]. In contrast, Tyrer's double blind crossover study showed that when lithium 


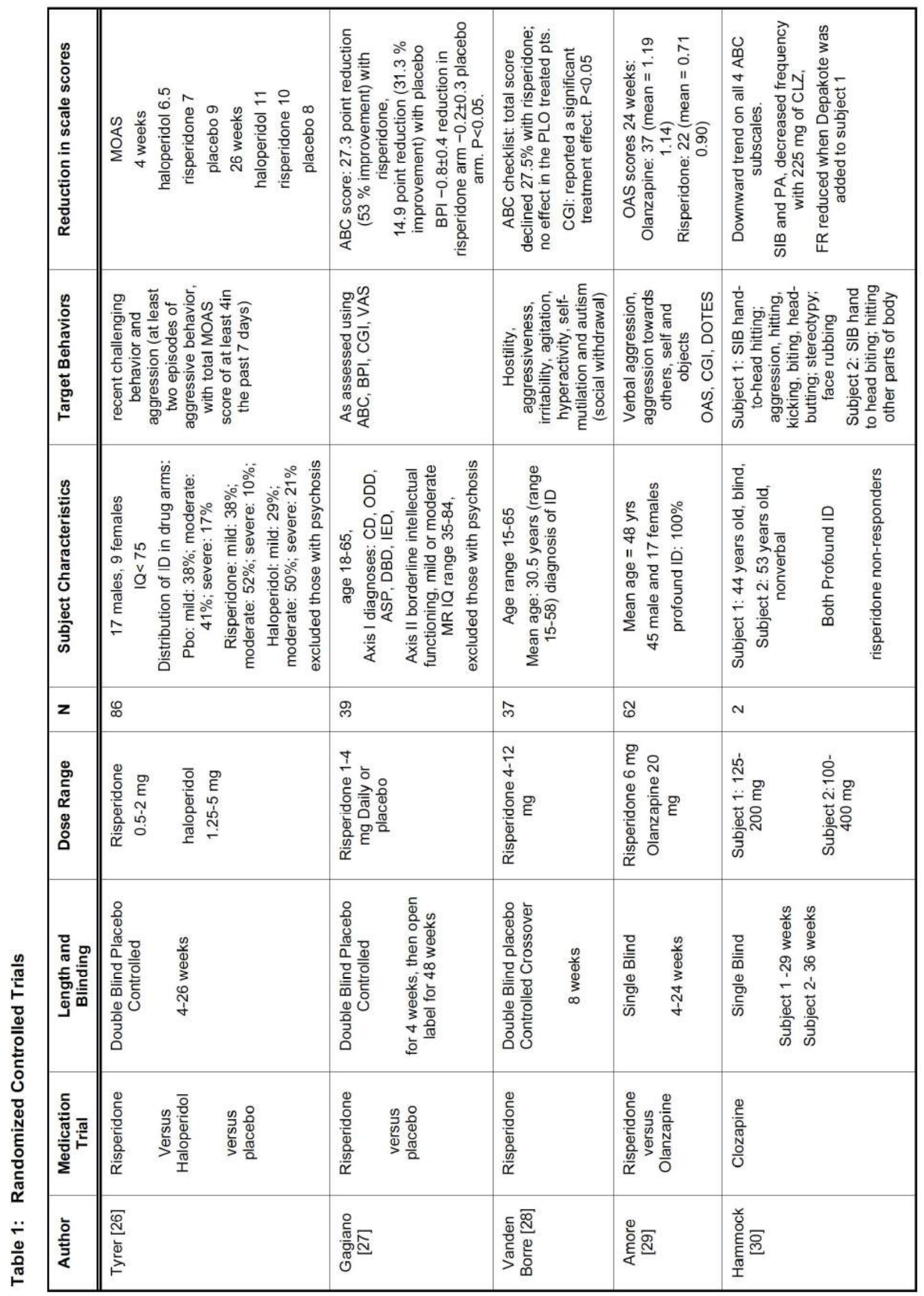




\begin{tabular}{|c|c|c|c|c|c|}
\hline 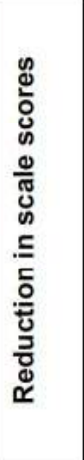 & 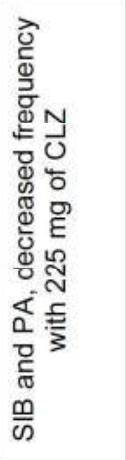 & 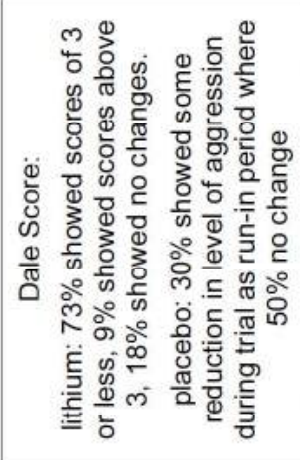 & 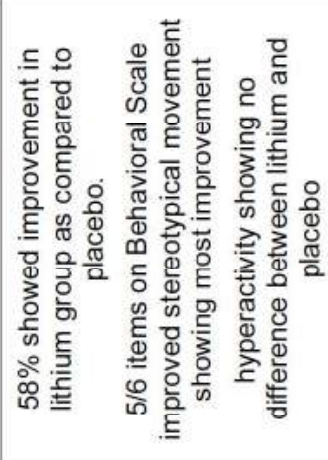 & 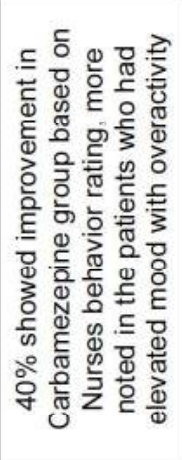 & 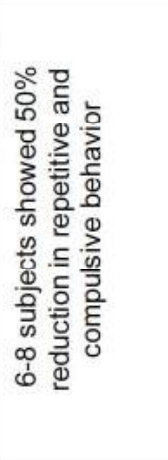 \\
\hline 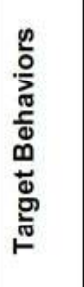 & 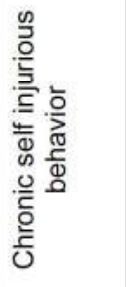 & 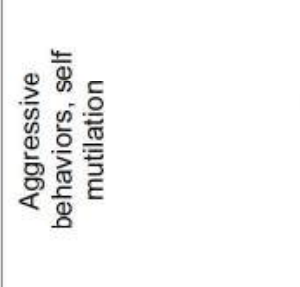 & 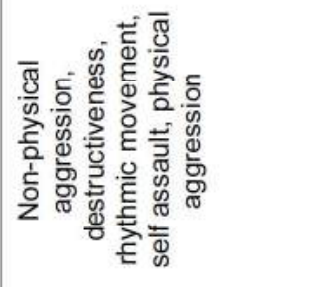 & 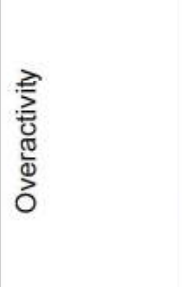 & 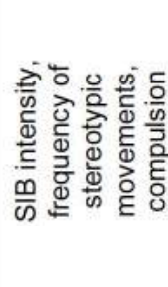 \\
\hline 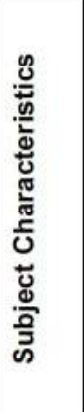 & 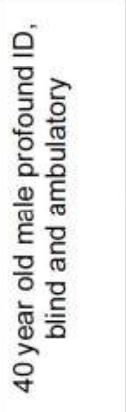 & 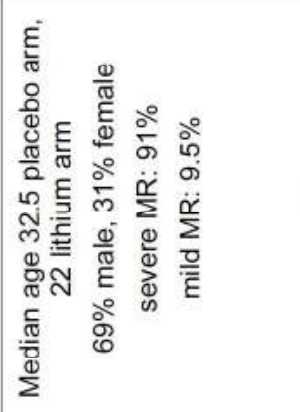 & 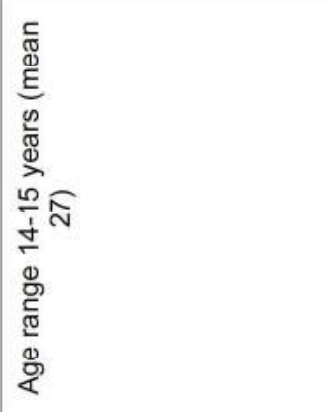 & 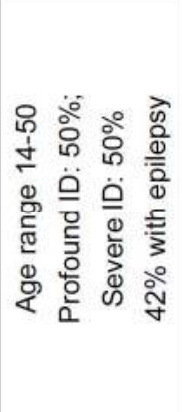 & 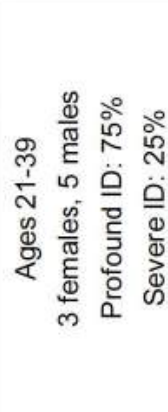 \\
\hline$z$ & - & テ & $\stackrel{2}{\sim}$ & $\cong$ & $\infty$ \\
\hline 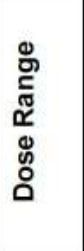 & $\begin{array}{l}\text { बे } \\
\frac{0}{0} \\
\text { E } \\
\underline{1} \\
\stackrel{1}{-}\end{array}$ & 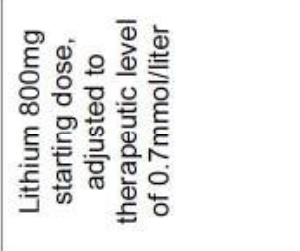 & 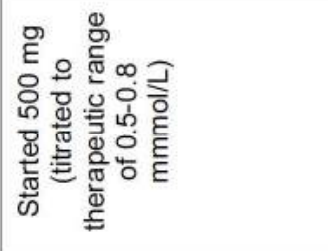 & 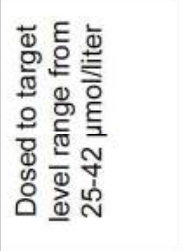 & 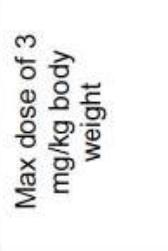 \\
\hline 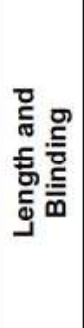 & 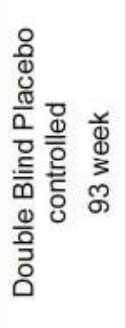 & 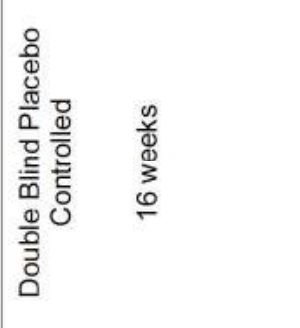 & 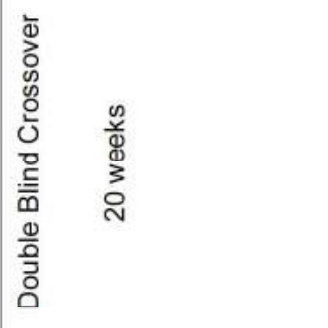 & 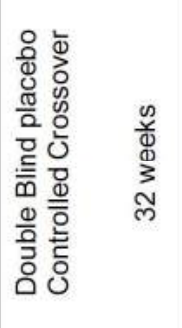 & 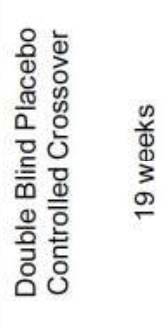 \\
\hline 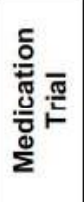 & $\begin{array}{l}\frac{9}{\frac{1}{2}} \\
\text { I } \\
\frac{0}{0}\end{array}$ & 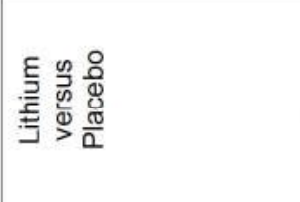 & 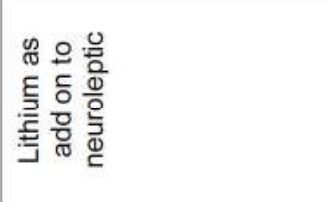 & 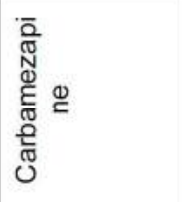 & 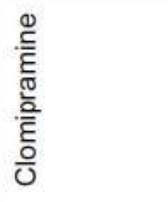 \\
\hline 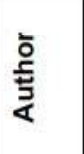 & 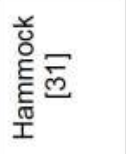 & 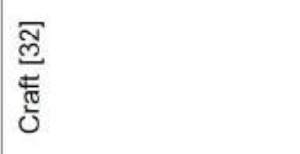 & 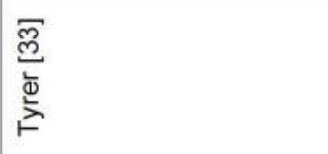 & 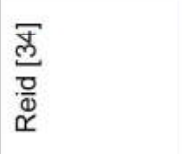 & $\frac{\sqrt{m}}{\frac{\infty}{3}}$ \\
\hline
\end{tabular}


was added on to a first generation antipsychotic, $58 \%$ of subjects had reduction in symptoms of destructiveness, self assault, rhythmic movements and physical aggression, as compared to placebo based on the behavior symptom checklist $(p<0.05)$ [33]. Factors associated with good response to lithium were 1) less than one aggressive episode per week prior to treatment, overactivity, stereotypic behavior, female sex and epilepsy. In both lithium studies, no patients became toxic and the side effects did not necessitate discontinuation or a reduction in lithium.

Carbamezapine in a double blind placebo controlled crossover study showed $40 \%$ improvement in overactivity. It was noted that patient's whose overactivity improved also had elevated mood prior to treatment $(p<0.05)$ [34]. Three patients were on additional psychotropic medications. There was no relationship between response to carbamazepine and the presence or absence of epilepsy [34].

\section{Antidepressants}

Clomipramine was the only antidepressant studied in a randomized placebo controlled crossover design. This study targeted self-injurious behaviors in subjects with profound and severe ID and did not target aggressive behaviors towards others or property. The design involved a titration up phase, maintenance and titration down. Between 6-8 subjects showed 50\% reduction in aggressive behaviors but no significant differences were found between treatment and placebo groups [35].

\section{Open Label Prospective Studies}

10 prospective studies were found were found using second generation antipsychotics (5), mood stabilizers (1) and antidepressants (4), and the findings are summarized in Table 2.

\section{Second Generation Antipsychotics}

The most studied medication was risperidone, with 5 prospective studies examining its efficacy in reduction of aggressive symptoms [36-40]. All subjects in these studies had ranges of ID from moderate to severe with the exception of the Durst study where IQs were not provided. All studies showed a reduction in symptoms of aggression with risperidone. There was one study in which subjects were nonverbal [36]. One study included subjects with Prader-Willi Syndrome, and the subject with the most reduction in aggression was also on androgen therapy and eltroxin prior to risperidone treatment [37]. Risperidone caused side effects of sedation, weight gain, akathisia and pseudoparkinsonim in some subjects [38], and reduction in tardive dyskinesia in other subjects [39]. Risperidone augmenting or replacing a first generation antipsychotic showed no change in aggression but improvements in side effects [40].

\section{Mood Stabilizers}

One open label prospective study showed subjects with aggression improve with valproic acid as an add to their current medication regimen [41]. The most common psychiatric diagnosis was mood disorder and eight patients had epilepsy or history of epilepsy.

\section{Antidepressants}

Three antidepressants, Fluoxetine [42, 43] and Paroxetine [44], Fluvoxamine [45] were studied in an open label prospective design. Bodfish et al. targeted compulsive behaviors of self injury. $44 \%$ of subjects responded to fluoxetine with reduction in suicidal ideation and aggression based on a facility-wide behavior management intervention monitoring system. Of note, $94 \%$ were receiving first generation antipsychotics throughout the course of their treatment [42]. Troisi reported aggression worsening in $47 \%$ of patients on fluoxetine [43].

Paroxetine in an open label prospective study showed that $62 \%$ of subjects responded on aggression severity and $42 \%$ on aggression frequency [44]. Based on individualized behavior logs, the largest change from baseline was in aggression frequency. Eight of these patients remained on their primary medications in this trial. Fluvoxamine did not show a significant reduction from placebo, and side effects were not significantly different [45].

\section{Open Label Retrospective Studies}

13 studies were found using an open label retrospective design using second generation antipsychotics (6), mood stabilizers (5) and antidepressants (2), the findings are summarized in Table 3.

\section{Second Generation Antipsychotics}

The most commonly studied second generation antipsychotic was risperidone and in retrospective studies also showed a reduction in aggression. Risperidone had a particular therapeutic window in doses of $6-8 \mathrm{mg}$ a day. In this particular study, $88 \%$ of subjects were on other psychotropics [46]. Reudrich showed that risperidone, compared to olanzapine and 


\begin{tabular}{|c|c|c|c|c|c|}
\hline 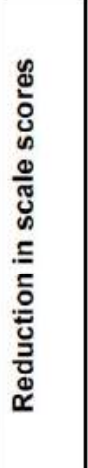 & 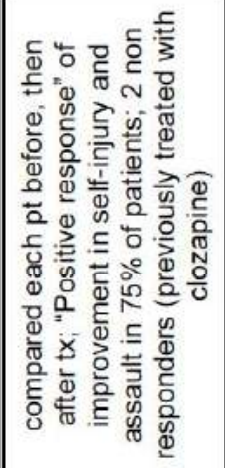 & 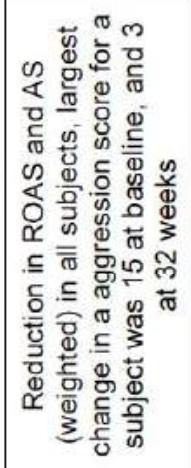 & 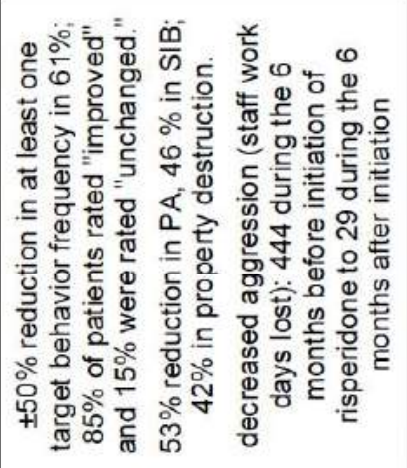 & 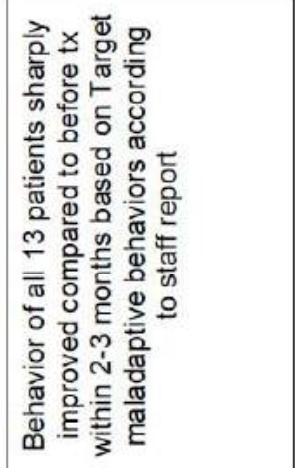 & 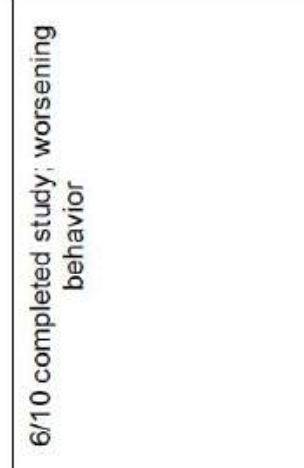 \\
\hline 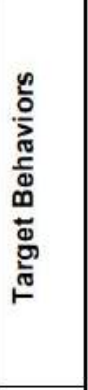 & 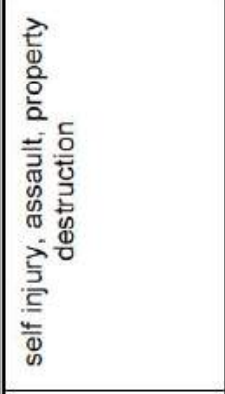 & 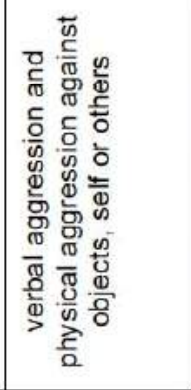 & 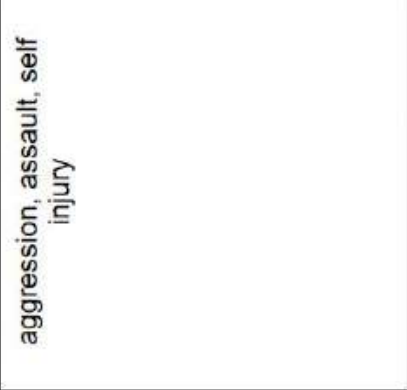 & 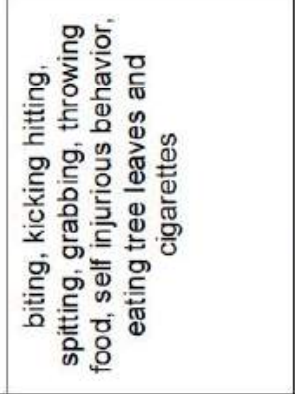 & 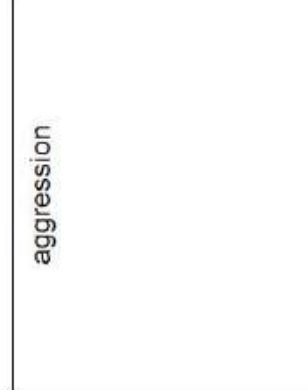 \\
\hline 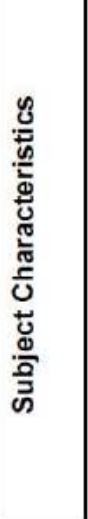 & 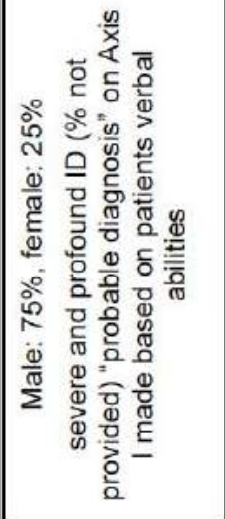 & 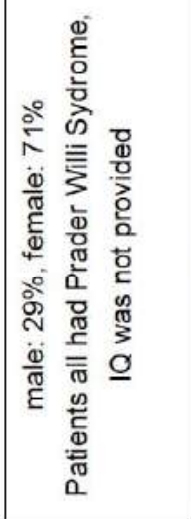 & 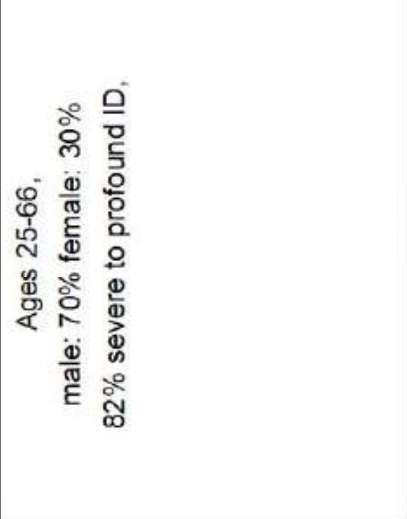 & 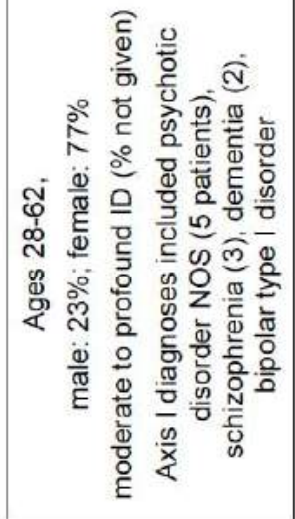 & 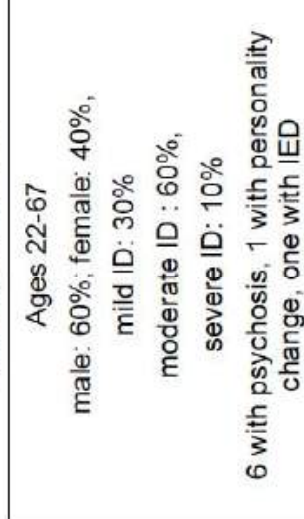 \\
\hline$z$ & $\infty$ & $\lambda$ & ल) & $\stackrel{m}{\stackrel{m}{2}}$ & 운 \\
\hline 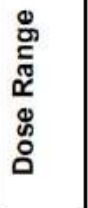 & 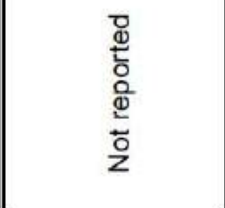 & 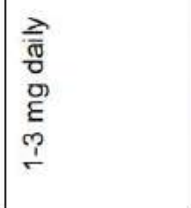 & 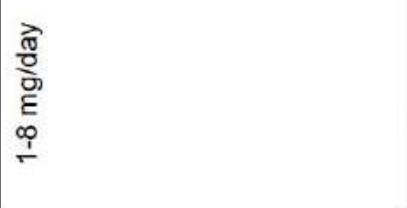 & 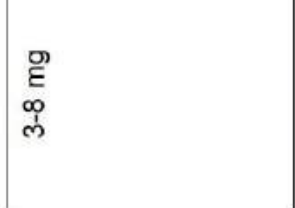 & 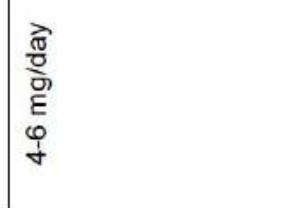 \\
\hline 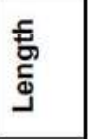 & 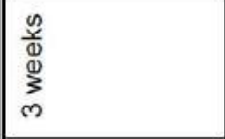 & 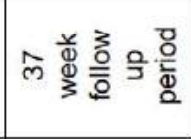 & ○总 & 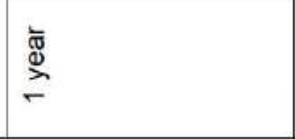 & 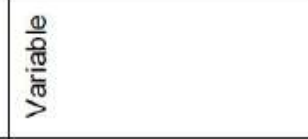 \\
\hline 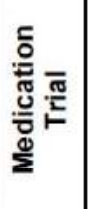 & 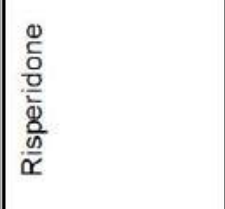 & 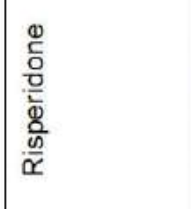 & 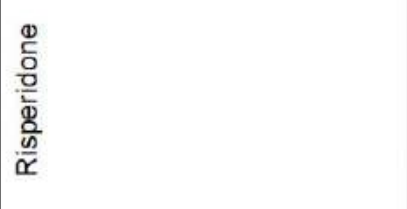 & 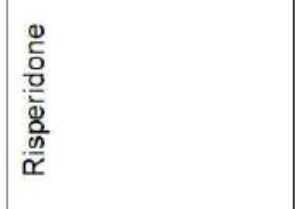 & \begin{tabular}{|l|} 
\\
$\frac{0}{5}$ \\
$\frac{\partial}{0}$ \\
$\frac{\partial}{0}$ \\
$\frac{0}{\alpha}$ \\
\end{tabular} \\
\hline 高 & 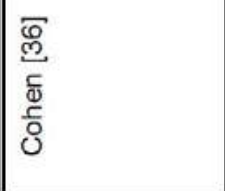 & 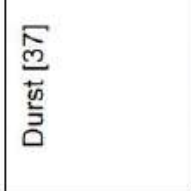 & 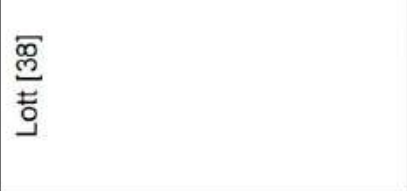 & 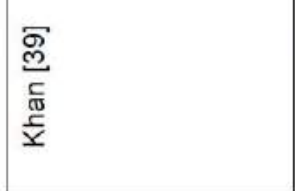 & 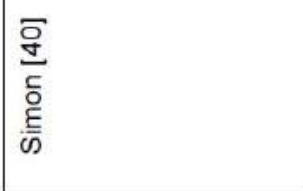 \\
\hline
\end{tabular}




\begin{tabular}{|c|c|c|c|c|c|}
\hline 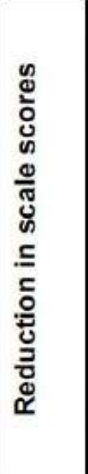 & 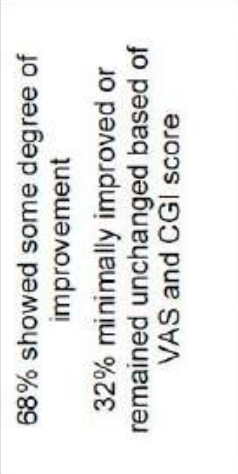 & 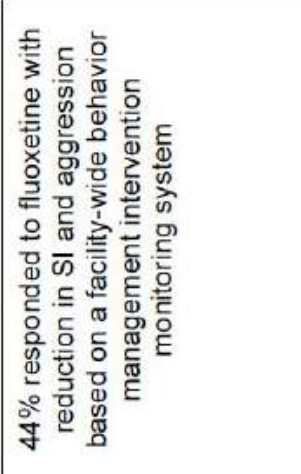 & 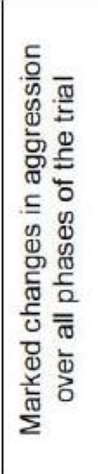 & 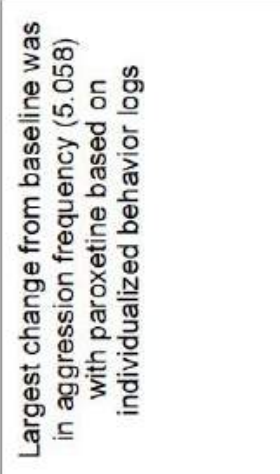 & 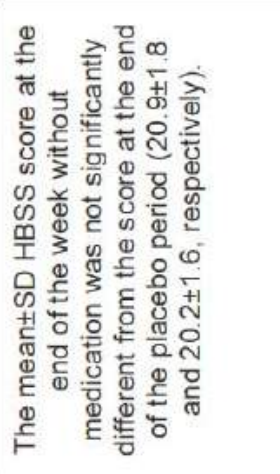 \\
\hline 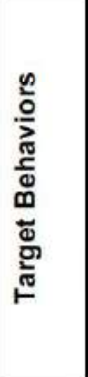 & 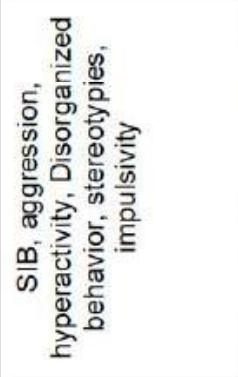 & 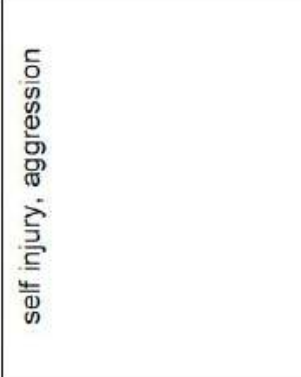 & 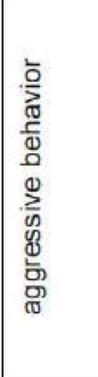 & 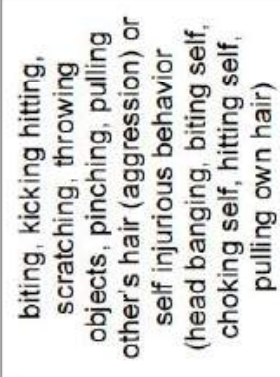 & 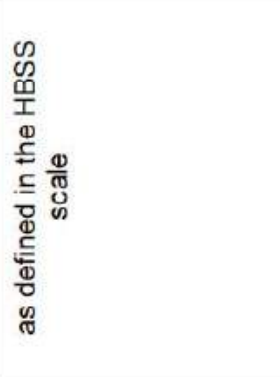 \\
\hline 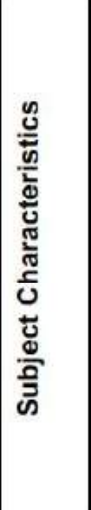 & 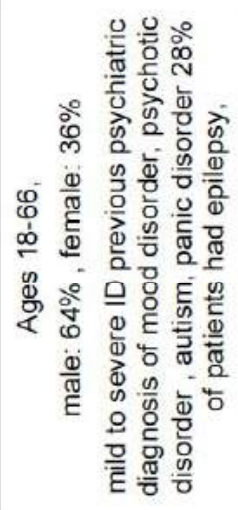 & 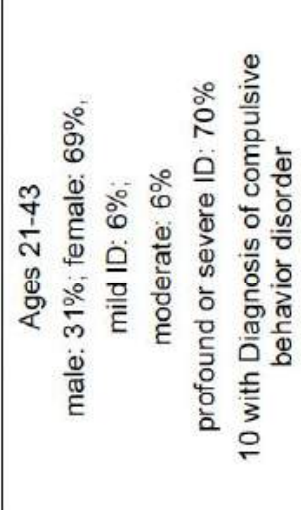 & 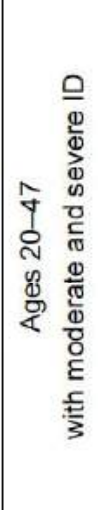 & 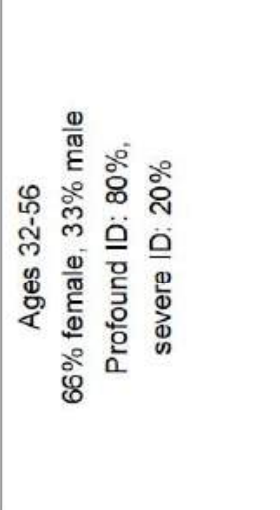 & 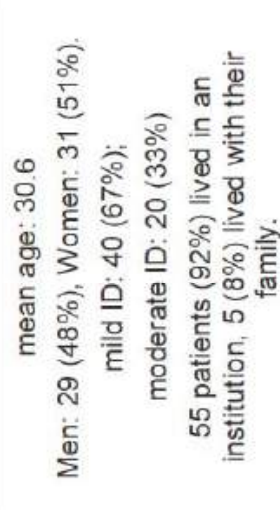 \\
\hline$z$ & $\stackrel{\infty}{\sim}$ & 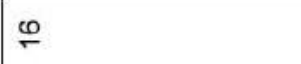 & $\stackrel{9}{\circ}$ & $\stackrel{\circ}{\llcorner}$ & 8 \\
\hline 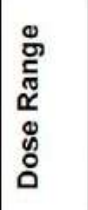 & 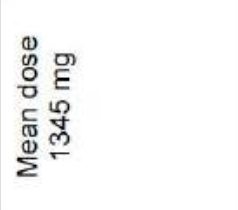 & 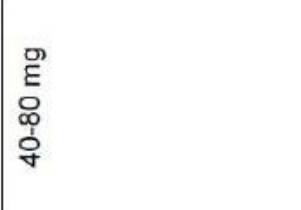 & 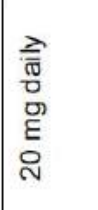 & 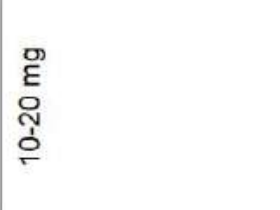 & 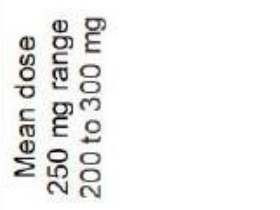 \\
\hline 哥 & 空 & $\begin{array}{l}\text { f } \\
\text { है } \\
\text { ह } \\
\text { g }\end{array}$ & $\begin{array}{l}n \\
\frac{n}{0} \\
\stackrel{0}{0} \\
\infty \\
\infty\end{array}$ & 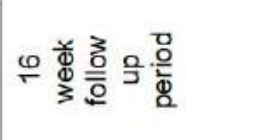 & 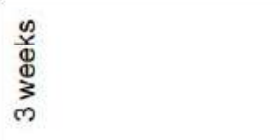 \\
\hline 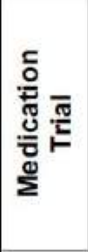 & 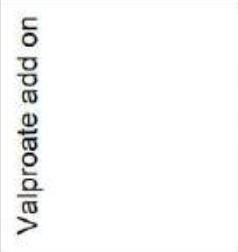 & 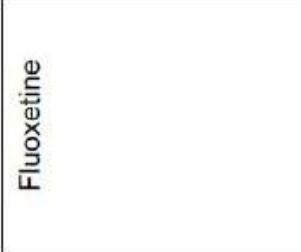 & 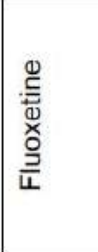 & 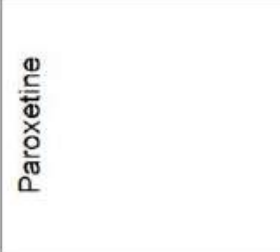 & 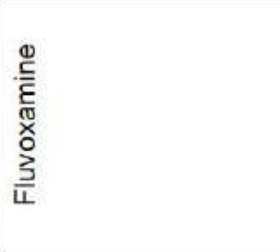 \\
\hline 高 & 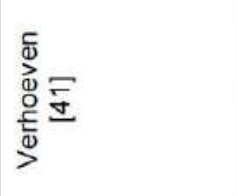 & 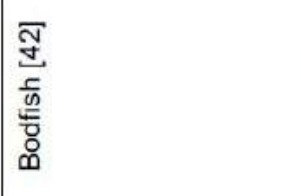 & 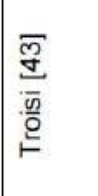 & 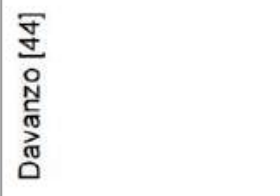 & 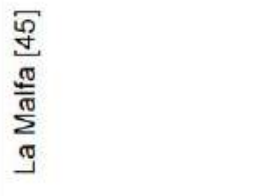 \\
\hline
\end{tabular}




\begin{tabular}{|c|c|c|c|c|c|c|c|}
\hline 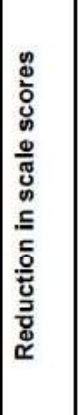 & 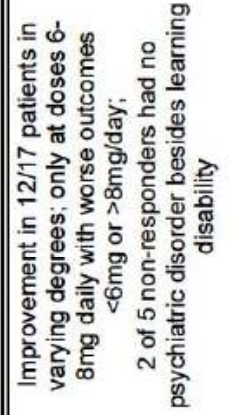 & 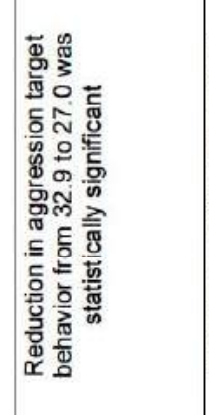 & 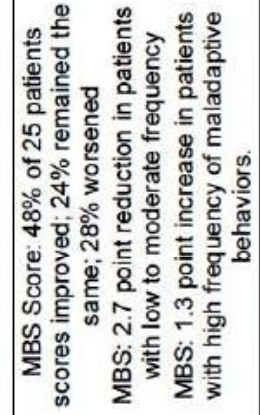 & 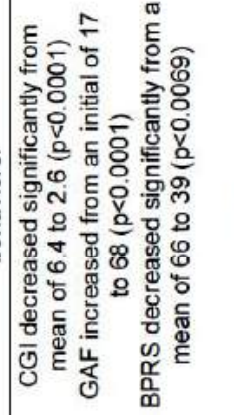 & 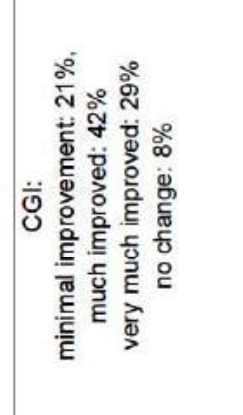 & 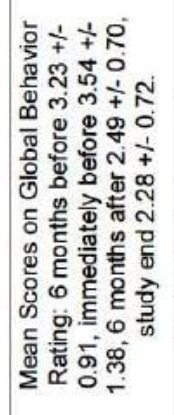 & 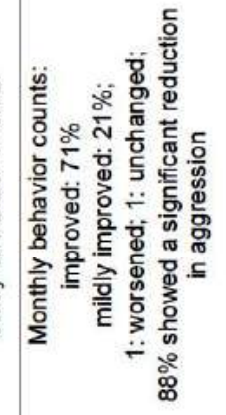 \\
\hline 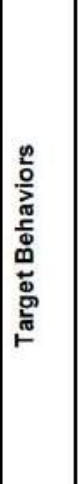 & 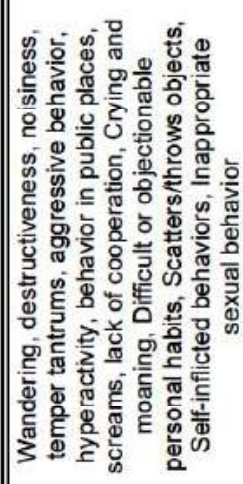 & 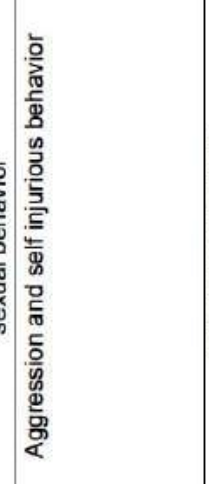 & 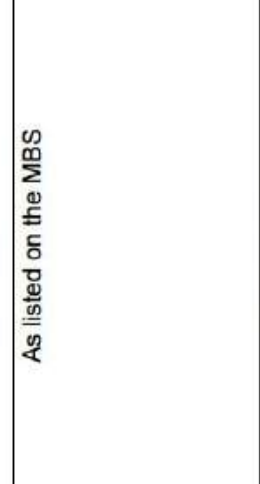 & 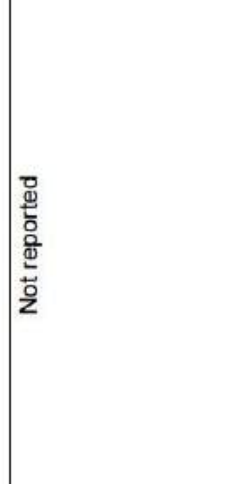 & 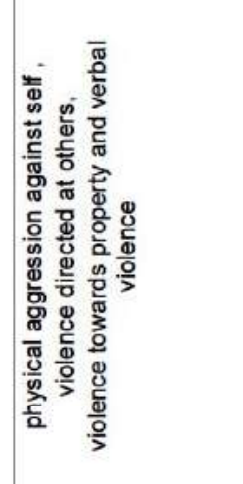 & 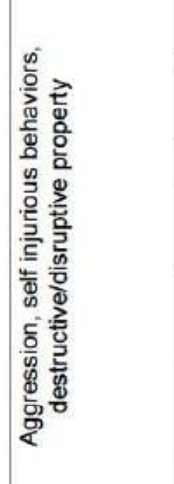 & 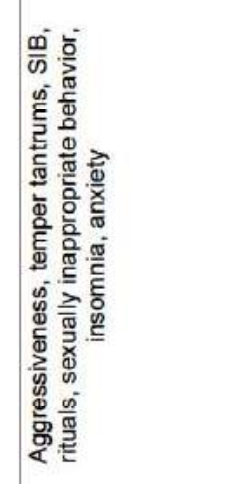 \\
\hline & 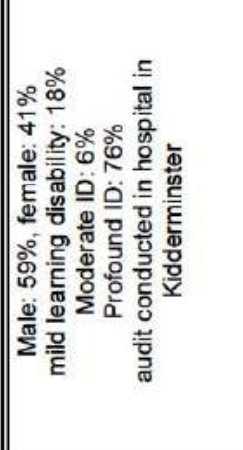 & 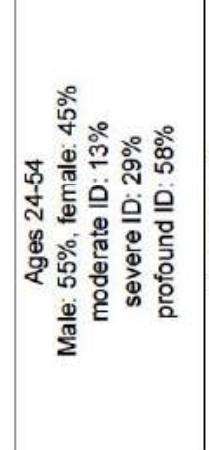 & 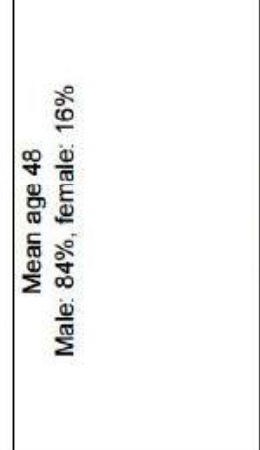 & 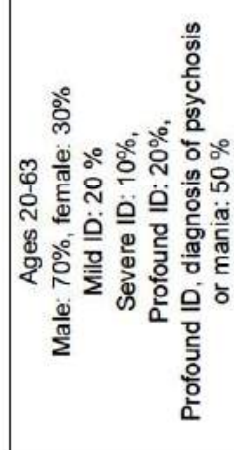 & 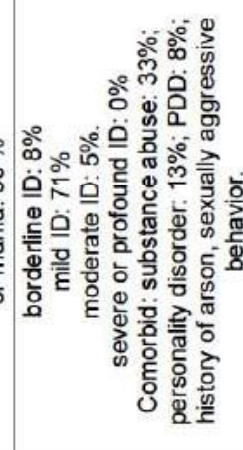 & 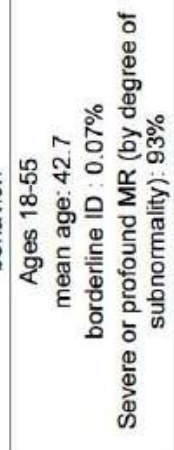 & 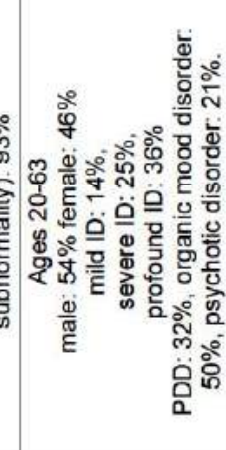 \\
\hline$z$ & $=$ & $\bar{m}$ & け & $\because$ & ম & ก & $\infty$ \\
\hline & 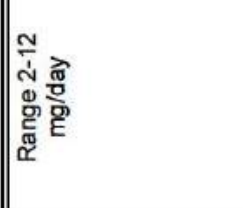 & 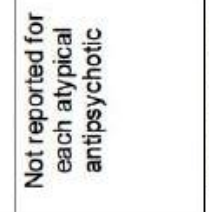 & 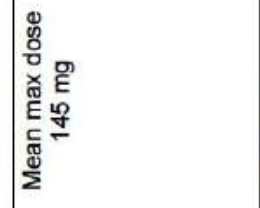 & 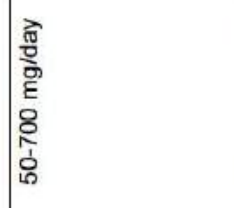 & 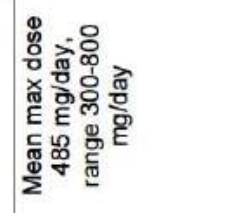 & 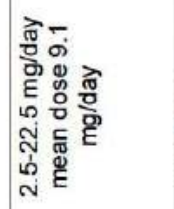 & 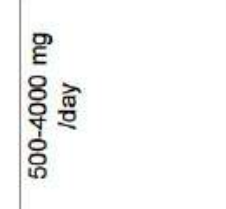 \\
\hline & 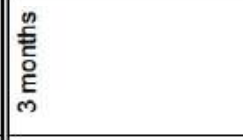 & 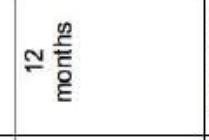 & 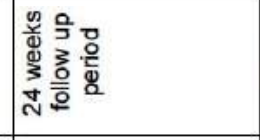 & 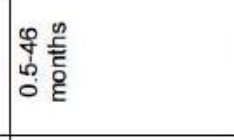 & 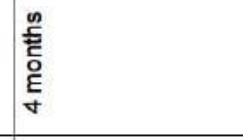 & 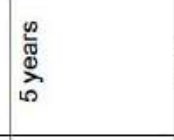 & 总 \\
\hline 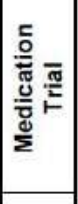 & $\frac{\square}{\frac{0}{5}}$ & 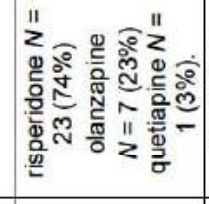 & 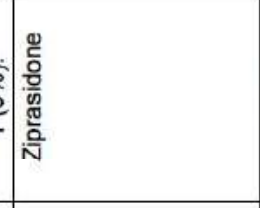 & 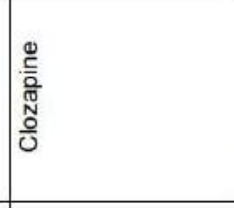 & 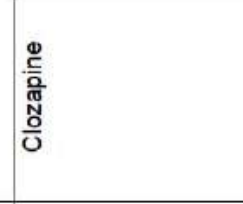 & 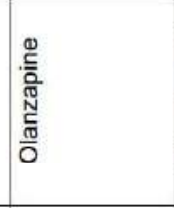 & 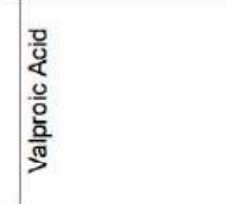 \\
\hline $\begin{array}{l}\frac{5}{5} \\
\frac{5}{0} \\
\frac{5}{2} \\
\frac{4}{4}\end{array}$ & 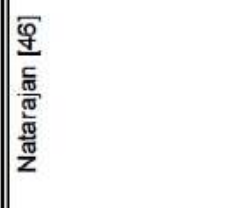 & 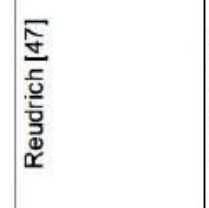 & 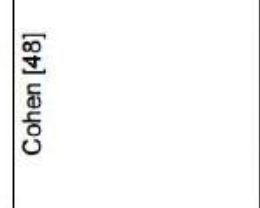 & 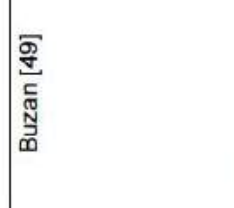 & 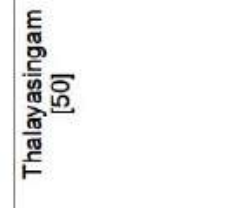 & 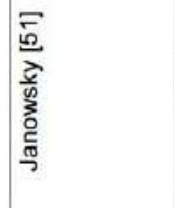 & 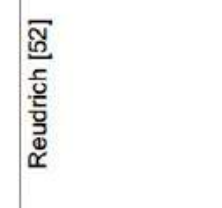 \\
\hline
\end{tabular}




\begin{tabular}{|c|c|c|c|c|c|c|}
\hline 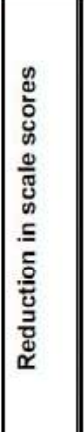 & 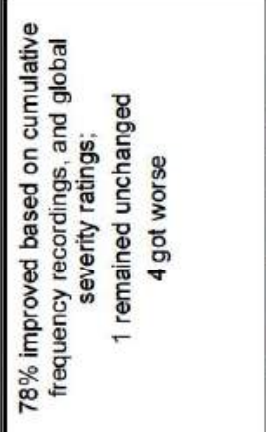 & 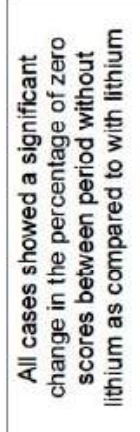 & 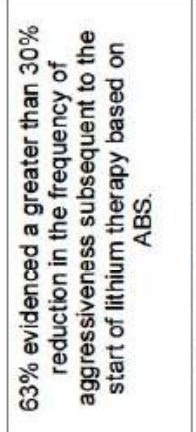 & 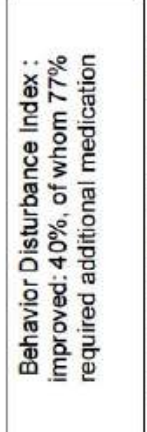 & 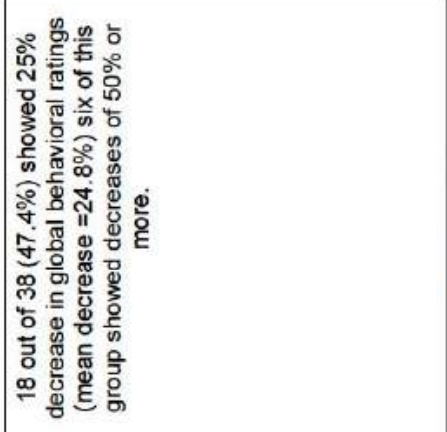 & 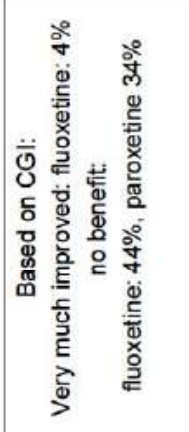 \\
\hline 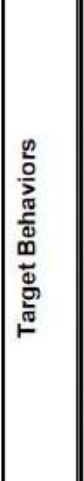 & 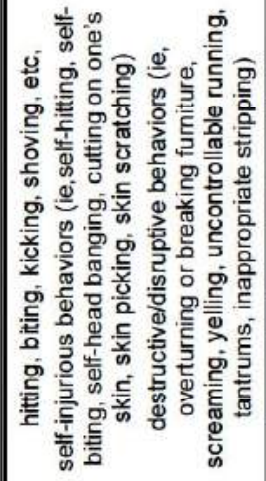 & 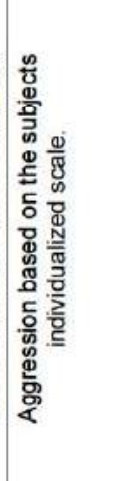 & 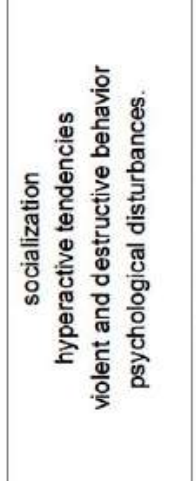 & 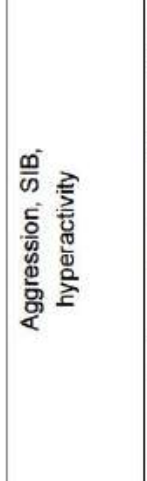 & 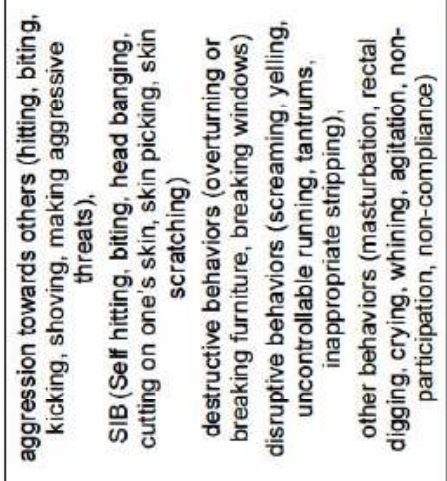 & 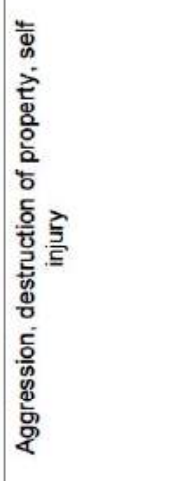 \\
\hline 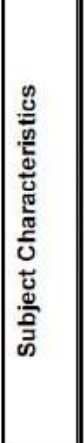 & 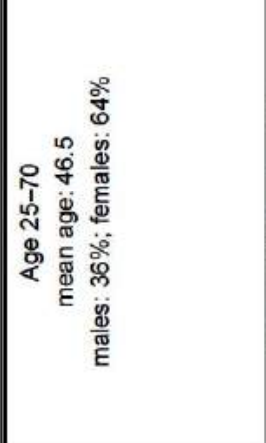 & 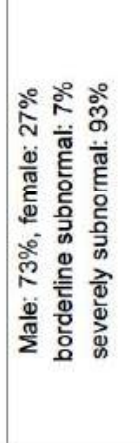 & 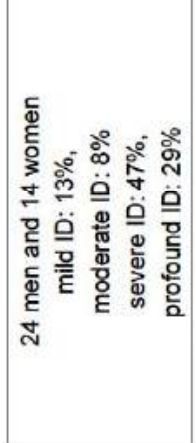 & 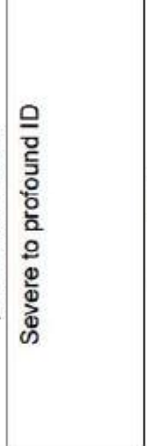 & 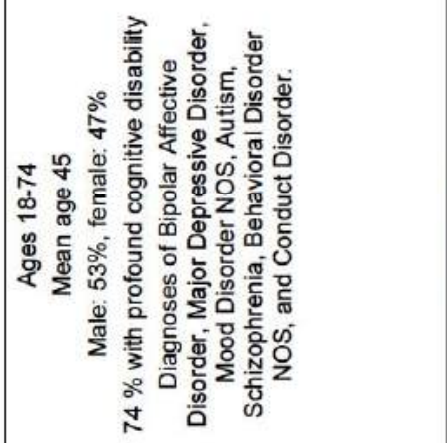 & 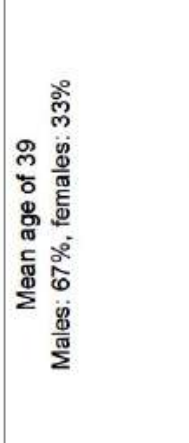 \\
\hline$z$ & $\approx$ & $\cong$ & ळ & 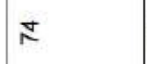 & ळ & ळ \\
\hline 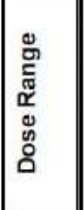 & 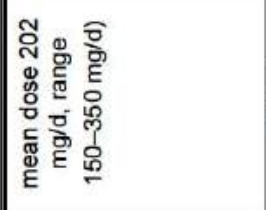 & 章 & 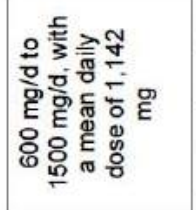 & 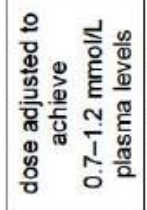 & 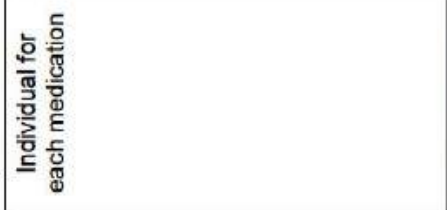 & 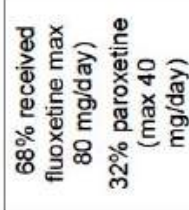 \\
\hline 言 & 总 & 总 & 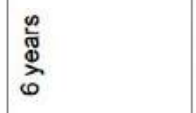 & 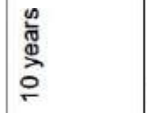 & 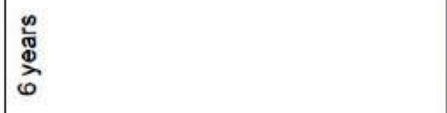 & 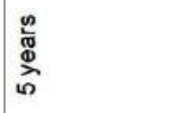 \\
\hline 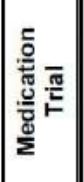 & 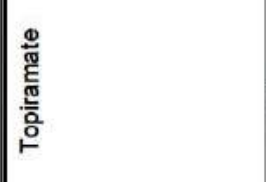 & 莺 & ह & 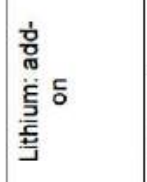 & 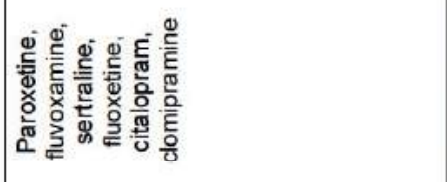 & 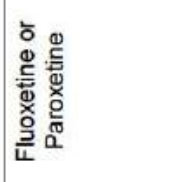 \\
\hline 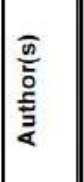 & 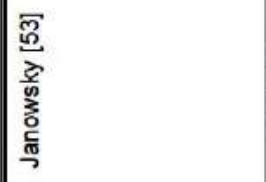 & 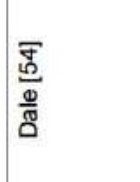 & 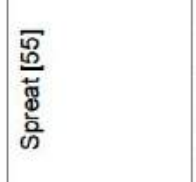 & 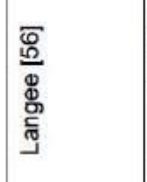 & 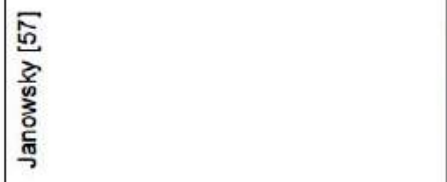 & 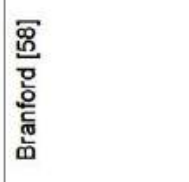 \\
\hline
\end{tabular}


quetiapine showed $74 \%$ more reduction in aggression when added to pre-existing psychotropics [47]. Ziprasidone showed that $48 \%$ of symptoms improved along with reduced adverse effects. Significant weight loss and reduction in total cholesterol and triglycerides was noted in the subjects receiving ziprasidone [48].

Clozapine showed reductions in CGI, GAF and BPRS in Buzan's study; however $70 \%$ were on mood stabilizers concurrently [49]. All subjects had psychiatric diagnoses of psychosis or mania. Half the subjects experienced sedation and hypersalivation, but these symptoms were dose dependent, transient, and not sufficient to terminate treatment. Another clozapine study showed improvement in aggression with clozapine use, and no significant side effects were noted in $42 \%$ of patients [50]. Olanzapine added on to a first generation antipsychotic, mood stabilizer or antidepressant showed improvement though subjects who were on olanzapine for more than 6 months experienced weight gain [51].

\section{Mood Stabilizers}

The search yielded 5 studies of mood stabilizers (lithium, valproic acid and topiramate) in an open label retrospective design. All showed a reduction in aggressive behaviors. In studies examining valproic acid [52] and topiramate [53], subjects were on other concurrent psychotropics medications (including lithium/anticonvulsants). Three studies on Lithium were found [54-56]. Dale's retrospective review on lithium showed reduction in certain behaviors in $73 \%$ of subjects; individualized rating scales were devised for 6 subjects showing reduction $(p<0.05)$ within 9 weeks of treatment. One subject developed tardive dyskinesia which was the cause for discontinuation of the lithium, but otherwise no other side effects were reported [54]. Subjects in Spreat's lithium study had a mean daily dose of $1142 \mathrm{mg} /$ day and it was reported those with higher serum lithium levels had a more favorable response to the medication [55]. Langee showed a reduction in aggression, however the majority of subjects required additional medications [56].

\section{Antidepressants}

One retrospective chart review [57] examined 5 SSRIs (paroxetine, fluvoxamine, sertraline, fluoxetine, citalopram) and the tricyclic antidepressant clomipramine. Use of these serotinergic agents resulted in improvement in various ratings. Three months after initiation of the antidepressant, many of the SSRI doses were not maximized. These subjects were on other psychotropics including antipsychotics, mood stabilizers or beta blockers. Conversely, in Branford's study, fluoxetine and paroxetine showed overall no change in aggressive behavior and $25 \%$ of subjects got worse with treatment [58].

\section{Case Series and Case Reports}

A total of 8 case reports and case series were found using second generation antipsychotics (2), mood stabilizers (3), and antidepressants (3), the findings are summarized in Table 4.

\section{Second Generation Antipsychotics}

Two case reports were found examining second generation antipsychotics. Brahm reports risperidone use in a 36 year old man with a history of fecal smearing as a means of nonverbal aggression [59]. The number of episodes of fecal smearing decreased post risperidone treatment. The subject was also on valproic acid, trazodone and naltrexone. Kamal reports on a 32 year old man with moderate ID whose aggressive behaviors of property destruction, self injurious and aggressive behaviors improved with 350 $\mathrm{mg}$ of clozapine [60]. It was noted that the reduction of his aggressive behaviors occurred concurrent with the reduction in his psychotic symptoms [60].

\section{Mood Stabilizers}

Two case series have been conducted for Lithium, both reporting on inpatient subjects who had failed trials of psychotropics [62], (Goetzl, Sovner). These subjects were all hospitalized due to dangerous behaviors including fighting with peers, elopement from home, school and aggression. In all cases, lithium showed improvement in aggressive behaviors. Side effects of nausea, diarrhea and tardive dyskinesia and bed wetting (one subject) were reported but did not necessitate the discontinuation of treatment. Mattes studied valproate in 2 individuals with mild ID, whose outburst behaviors improved after treatment at doses of $250 \mathrm{mg}$ TID [63]. Both subjects were concurrently on neuroleptics and one additionally on lithium. Though the valproate levels were subtherapeutic at $250 \mathrm{mg}$ TID, increasing the dose to $1000 \mathrm{mg}$ showed no improvement in behaviors for one patient.

\section{Antidepressants}

One case series reported on subjects in whom self injury and aggression improved either with sertraline or clomipramine. Luiselli reported sertraline at doses of $250 \mathrm{mg} /$ day resulted in improvement in aggression in one subject [64]. Trazodone was studied in two 


\begin{tabular}{|c|c|c|c|c|c|c|c|c|c|}
\hline 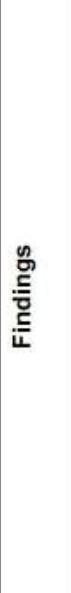 & 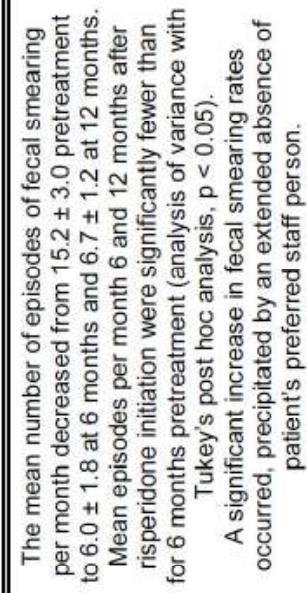 & 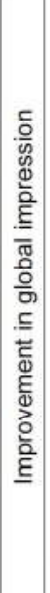 & 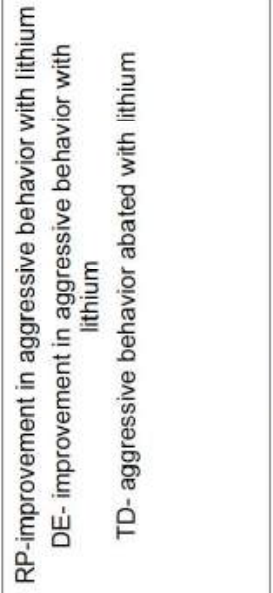 & 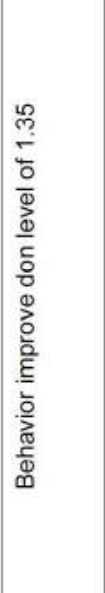 & 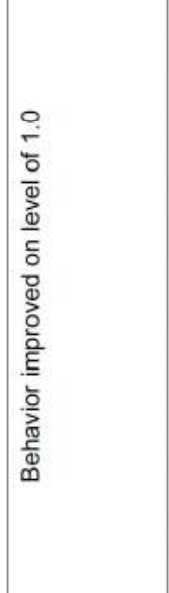 & 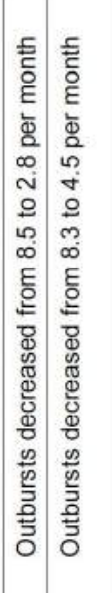 & 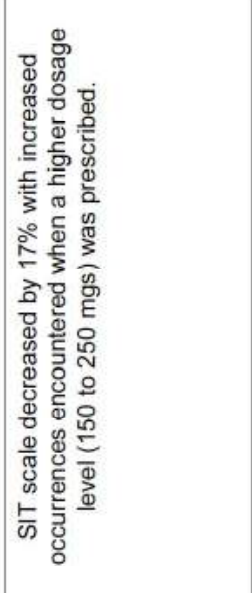 & 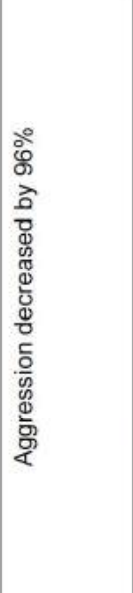 & 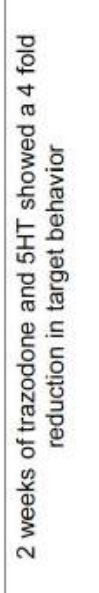 \\
\hline 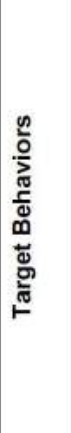 & 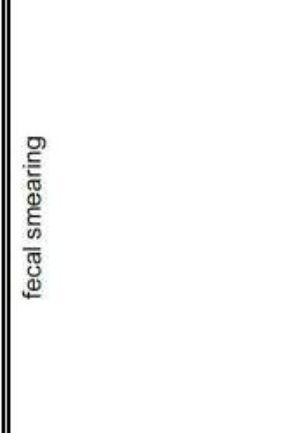 & 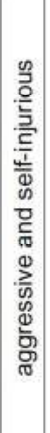 & 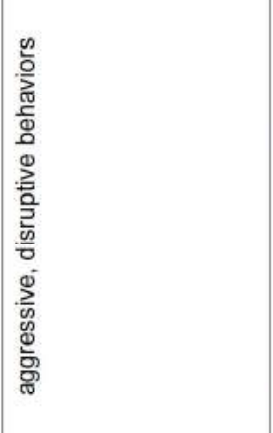 & 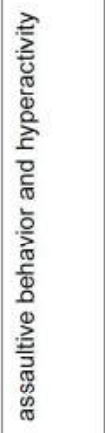 & 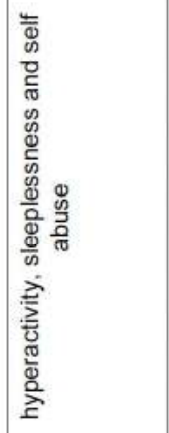 & 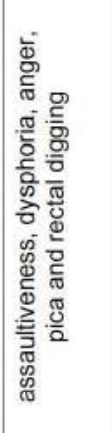 & 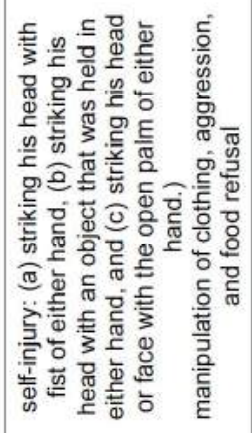 & 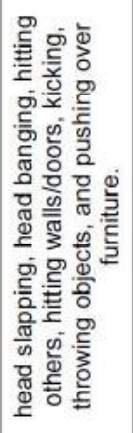 & 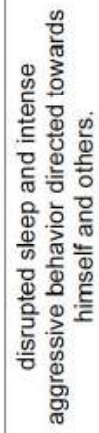 \\
\hline 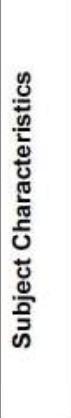 & 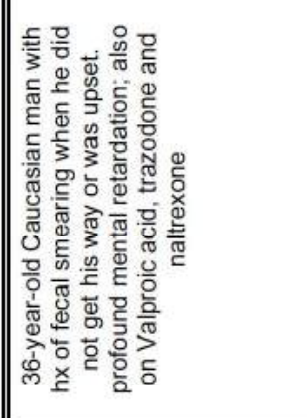 & 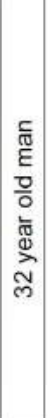 & 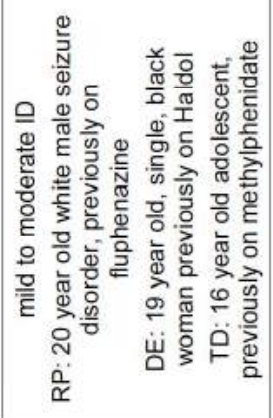 & 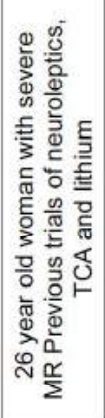 & 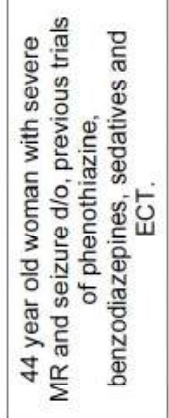 & 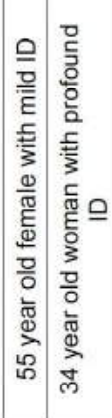 & 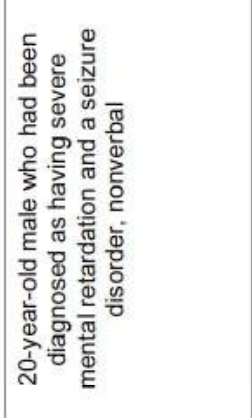 & 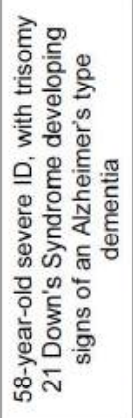 & 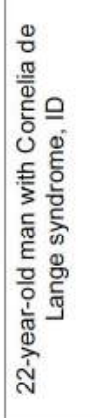 \\
\hline$z$ & - & - & $m$ & n & & $\sim$ & n & - & - \\
\hline 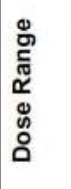 & 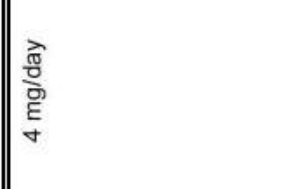 & 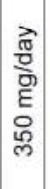 & 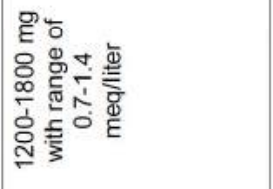 & 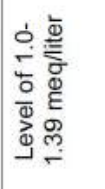 & & 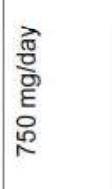 & 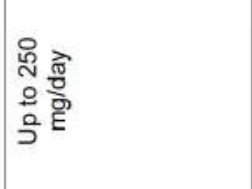 & 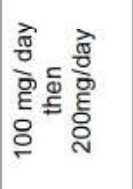 & 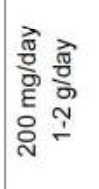 \\
\hline $\begin{array}{l}\text { 䓌 } \\
\text { 志 } \\
\text { తl }\end{array}$ & 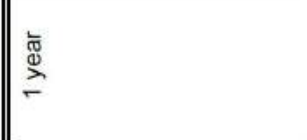 & 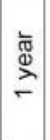 & & 莺 & 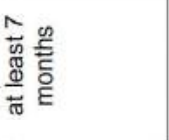 & 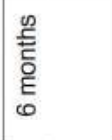 & 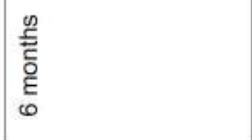 & 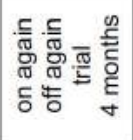 & $\begin{array}{l}\infty \\
\stackrel{\infty}{0} \\
\Phi \\
\sum_{0} \\
0\end{array}$ \\
\hline 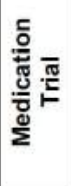 & 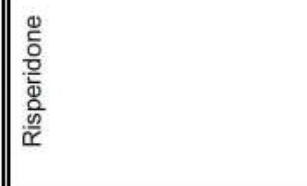 & 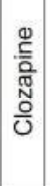 & 占 & 点 & & 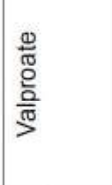 & 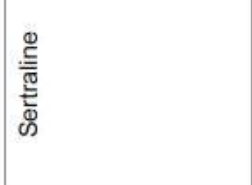 & 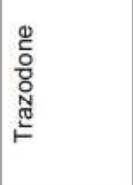 & 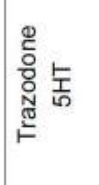 \\
\hline $\begin{array}{l}\widehat{n} \\
\frac{n}{0} \\
\frac{c}{z} \\
\dot{z}\end{array}$ & $\frac{\sqrt{\frac{\sigma}{6}}}{\underline{E}}$ & 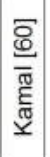 & $\begin{array}{l}\overline{\overline{0}} \\
\frac{\overline{\mathrm{N}}}{\mathrm{N}} \\
0 \\
0\end{array}$ & & 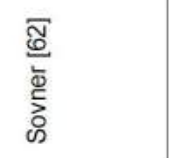 & 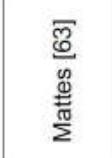 & 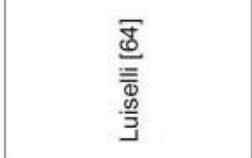 & 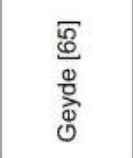 & 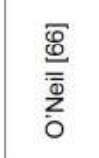 \\
\hline
\end{tabular}


subjects $[65,66]$. In both subjects trazodone was associated with a reduction in aggressive behaviors. Geyde used an on again off again trial design [65]. In O'Neil's study, trazodone was used in conjunction with $5 \mathrm{HT}$ and the subject was being cross titrated from imipramine [66].

\section{DISCUSSION}

This review examined the various study designs of three drug classes (second generation antipsychotics, mood stabilizers and antidepressants) used to treat aggression in patients with ID. The aim was to determine based on the most rigorous study design which medications would suggest the best evidence for efficacy. This patient population is very difficult to examine in a literature review as it is a population that is heterogeneous and for whom the diagnostic nomenclature has been in flux. Given the comorbidity of Axis I with ID diagnoses, it was imperative to attempt to homogenize the subjects in the studies, therefore, studies predominantly including autism spectrum/ pervasive developmental disorders and children with ID were excluded.

There are only 10 randomized controlled trials using these agents: second generation antipsychotics, mood stabilizers and antidepressants. There were two-arm studies comparing risperidone, clozapine, lithium, carbamezapine and clomipramine to placebo. Only 2 studies had more than 50 subjects: Amore $(n=62)$ [29] and Tyrer $(n=86)$ [26]. All but two of the 10 trials yielded statistically significant results [26, 35]. Risperidone and lithium were the two most studied agents and showed reduction in aggression showing the most statistically significant results. Given that these two agents were the most commonly studied in the most rigorous experimental design, it is suggested that risperidone and lithium prove efficacious for treatment of aggression in patients with ID.

There exists abundant data in either prospective or retrospective studies examining reduction of aggression in this patient population. Based on the existing literature, retrospective studies, consisting of mostly chart reviews, are most often reported; these studies do not reflect the rigor of experimental design seen in randomized controlled trials and lack a comparator arm. Several of these studies had no consistent longitudinal tracking of target behaviors using scales validated for aggression in ID, and there was no homogeneity of aggression scales used. As such, target behaviors might have varied from study to study and were often subjective reports from staff. Comparisons between studies could not be made as some focused on profound and severe ID whereas other studies focused on mild and moderate ID. Many studies targeted patients with severe and profound ID who had known communication limitations but were still diagnosed with axis I disorders on the psychotic or affective spectrum.

As very few randomized trials exist, it would be postulated that more case reports and case series would exist in the literature describing improvement in aggression with any of these agents, yet only a total of eight were found meeting the search criteria. This is likely due to the fact that a disproportionately larger number of reports have been written in children with ID or adults with autism spectrum/pervasive developmental disability.

There were several limitations to this review. All categories of experimental designs revealed that subjects received other medications (particularly as add-on to antipsychotics) with variations in types and dosing, resulting in a confounding bias. Several studies included subjects with epileptic disorders which may have (in pre, post or ictal states) contributed to the aggressive and agitated behaviors seen in the sample size with improvement on certain agents that would treat both seizures and aggressive behavior. Relatively small sample sizes throughout classes of experimental designs suggest limited power. In several studies, not all agents used were maximized to therapeutic doses, which may have impacted the outcome on the aggression scales.

Given the limitation of communication skills in ID patients, it is difficult to determine patient reports of side effects from medications, potentially affecting compliance with treatment and dropout rates. Limited communication also leads to problems with informed consent. It was notable that only a few studies (e.g. Troisi [43]) made mention of a legal guardian signing for the patient. Given the complexity of assessing target symptoms in ID patients due to their limited communication skills, subjective rating scales make it difficult to assess for symptom reduction. Moreover, there was no homogeneity in aggression scales used across studies, and many of these scales used have not been validated for use in aggression with ID patients.

There remain several unanswered questions. Based on the data, comparing treatment response by gender 
cannot be determined. Results appear to be study specific and no conclusions can be drawn as to who would respond better to pharmacologic treatments. It might be postulated that elderly patients are more susceptible to side effects of medications, and that the cause of agitation in the elderly might often more be related to medical sources rather than psychiatric or environmental cause, though this was not particularly addressed in any study with the given age ranges. Additional studies that focus on particular populations would help to answer some of these questions.

It is well known that behavioral and environmental interventions are effective for challenging behaviors in the ID population. As Antonacci describes, behavioral interventions have been well studied with severe ID, however the challenges lie in implementing these interventions. He confirms environmental change and positive reinforcements are more effective than aversive consequences and punishment [67].

Given the prevalence of aggression in subjects with ID, it may not be realistic to expect to recruit larger sample sizes for future studies. Allowing for more objective and universal measures might encourage meta-analyses for stronger evidenced based recommendations.

\section{CONCLUSION}

This review confirms that pharmacological management of aggression in patients with ID is very much an area that is understudied. In a search of two decades of literature, there still exists a paucity of randomized controlled trials studying the most common agents used to treat this patient population. In the existing literature the two most studied agents in an randomized controlled experimental design are risperidone and lithium which suggests that these two agents may have efficacy for use in management of aggression in patients with ID. Additional research and a more standardized objective means of measurement are required to better serve this patient population.

\section{DISCLOSURES}

The authors Durga Roy MD, Pamela Hoffman MD, and Melissa Dudas, DO have no financial, proprietary or commercial disclosures. Author Alan Mendelowitz, $M D$ has the following disclosures: No financial disclosures or conflicts 2010, 2011, 2012, 2013. 2009 Speakers Bureau Jansen Pharmaceuticals, Pfizer Pharmaceuticals, Astra Zeneca Pharmaceuticals

\section{ACKNOWLEDGEMENT}

We would like to acknowledge informationist Katie Lobner for her assistance. We would also like to thank Dr. Andrew Angelino and Dr. Vani Rao for their support and guidance.

\section{REFERENCES}

[1] Lindenmayer JP. The pathophysiology of agitation. J Clin Psychiatry 2000; 61(Suppl 14): 5-10.

[2] Lakin KC, Hill BK, Hauber FA, et al. New admissions and readmissions to a national sample of public residential facilities. Am J Ment Defic 1983; 88(1): 13-20.

[3] Aman MG, Richmond G, Stewart AW, Bell JC, et al. The aberrant behavior checklist: factor structure and the effect of subject variables in American and New Zealand facilities. Am J Ment Defic 1987; 91(6): 570-8.

[4] Tsiouris, JA. Pharmacotherapy for aggressive behaviours in persons with intellectual disabilities: treatment or mistreatment? J Intellect Disabil Res 2010; (54)part 1: 1-16.

[5] Cooper SA, Smiley E, Jackson A, et al. Adults with intellectual disabilities: prevalence, incidence and remission of aggressive behaviour and related factors. J Intellect Disabil Res 2009; 53(3): 217-32. http://dx.doi.org/10.1111/j.1365-2788.2008.01127.x

[6] Emerson E, Kiernan C, Alborz A, et al. The prevalence of challenging behaviors: a total population study. Res Dev Disabil 2001; 22(1): 77-93. http://dx.doi.org/10.1016/S0891-4222(00)00061-5

[7] Meins W. Symptoms of major depression in mentally retarded adults. J Intellect Disabil Res 1995; 39(1): 41-45. http://dx.doi.org/10.1111/j.1365-2788.1995.tb00912.x

[8] Lowry MA, Sovner R. Severe behavior problems associated with rapid cycling bipolar disorder in two adults with profound mental retardation. J Intellect Disabil Res 1992; 36: 269-81. http://dx.doi.org/10.1111/j.1365-2788.1992.tb00515.x

[9] Khreim I, Mikkelsen E. Anxiety disorders in adults with mental retardation. Psych Annals 1997; 27(3): 175-81.

[10] Silka VR, Hauser MJ. Psychiatric assessment of the person with mental retardation. Psych Annals 1997; 27(3): 162-69.

[11] Ryan R, Sunada K. Medical evaluation of persons with mental retardation referred for psychiatric assessment. General Hospital Psych 1997; 19: 274-80. http://dx.doi.org/10.1016/S0163-8343(97)00023-6

[12] Barron J, Sandman CA. Paradoxical excitement to sedativehypnotics in mentally retarded clients. Am J Mental Deficiency 1985; 90(2): 124-29.

[13] Stavrakaki C, Mintsioulis G. Implications of a clinical study of anxiety disorders in persons with mental retardation. Psych Annals 1997; 27(3): 182-97.

[14] Kaplan HI, Sadock BJ, eds. Comprehensive Textbook of Psychiatry/V, Baltimore: Williams \& Wilkins 1989.

[15] Powers RE. Primary care assessment and management of aggressive behavior toward others for the adult with mental retardation and developmental disabilities. Bureau Geriatric Psych 2005.

[16] Matson JL, Bamburg JW, Mayville EA, et al. Psychopharmacology and mental retardation: a 10 year review (1990 -1999). Res Dev Disabil 2000; (21): 263-96. http://dx.doi.org/10.1016/S0891-4222(00)00042-1

[17] Singh AN, Matson JL, Hill BD, et al. The use of clozapine among individuals with intellectual disability: A review. Res Dev Disabil 2010; (31): 1135-41.

http://dx.doi.org/10.1016/j.ridd.2010.07.003 
[18] Singh AN, Matson JL, Cooper CL, et al. The use of risperidone among individuals with mental retardation: clinically supported or not? Res Dev Disabil 2005; (26): 20318.

http://dx.doi.org/10.1016/j.ridd.2004.07.001

[19] Radouco-Thomas M, Bolduc M, Brisson A, et al. Pilot study on the use of psychotropic medication in persons with mental retardation. Progr Neuro-Psychopharmacol Biol Psych 2004; 879-83.

http://dx.doi.org/10.1016/j.pnpbp.2004.05.029

[20] Deb S, Chaplin R, Sohanpal S, et al. The effectiveness of mood stabilizers and antiepileptic medication for the management of behavior problems in adults with intellectual disability: a systematic review. J Intellect Disabil Res 2008; 52(2): 107-13.

[21] Holden B, Gitlesen JP. Psychotropic medication in adults with mental retardation: prevalence, and prescription practices. Res Dev Disabil 2004; (25): 509-21. http://dx.doi.org/10.1016/j.ridd.2004.03.004

[22] Glazer WM. Olanzapine and the new generation of antipsychotic agents: patterns of use. J Clin Psych 1997; 58(Suppl 10): 18-21.

[23] Lott IT, McGregor M, Engelman L, Touchette P, Tournay A, Sandman $C$, et al. Longitudinal prescribing patterns for psychoactive medications in community-based individuals with developmental disabilities: utilization of pharmacy records. J Intellect Disabil Res 2004; 48(Pt 6): 563-71. http://dx.doi.org/10.1111/j.1365-2788.2004.00625.x

[24] Spreat S, Conroy JW, Jones JC. Use of psychotropic medication in Oklahoma: a statewide survey. Am J Ment Retard 1997; 102(1): 80-5. http://dx.doi.org/10.1352/08958017(1997)102<0080:UOPMIO>2.0.CO;2

[25] Spreat S, Conroy JW, Fullerton A. Statewide longitudinal survey of psychotropic medication use for persons with mental retardation: 1994 to 2000. Am J Ment Retard 2004; 109(4): 322-31.

http://dx.doi.org/10.1352/08958017(2004)109<322:SLSOPM $>2.0$. CO;2

[26] Tyrer P, Oliver-Africano PC, Ahmed Z, et al. Risperidone, haloperidol, and placebo in the treatment of aggressive challenging behaviour in patients with intellectual disability: a randomised controlled trial. Lancet 2008; 371(9606): 57-63. http://dx.doi.org/10.1016/S0140-6736(08)60072-0

[27] Gagiano C, Read S, Thorpe L. Short-and long-term efficacy and safety of risperidone in adults with disruptive behavior disorders. Psychopharmacology (Berl) 2005; 179(3): 629-36. http://dx.doi.org/10.1007/s00213-004-2093-2

[28] Vanden Borre R, Vermote R, Buttiens $M$, et al: Risperidone as add-on therapy in behavioural disturbances in mental retardation: a double-blind placebo-controlled cross-over study. Acta Psychiatr Scand 1993; 87: 167-71. http://dx.doi.org/10.1111/j.1600-0447.1993.tb03350.x

[29] Amore M, Bertelli M, Villani D, Tamborini S, Rossi M. Olanzapine vs. risperidone in treating aggressive behaviours in adults with intellectual disability: a single blind study. J Intellect Disabil Res 2011; 55(2): 210-18. http://dx.doi.org/10.1111/j.1365-2788.2010.01352.x

[30] Hammock R, Levine WR, Schroeder SR. Brief Report. Effects of Clozapine on Self-Injurious Behavior of Two Risperidone Nonresponders with Mental Retardation. J Autism Dev Disord 2001; 31(1): 109-13. http://dx.doi.org/10.1023/A:1005626100084

[31] Hammock RG, Schroeder SR, Levine WR. The effect of clozapine on self-injurious behavior. J Autism Dev Disord 1995; 25: 611-26. http://dx.doi.org/10.1007/BF02178191
Craft M, Ismail IA, Krishnamurti D, et al. Lithium in the treatment of aggression in mentally handicapped patients: a double-blind trial. Br J Psych 1987; 150: 685-89. http://dx.doi.org/10.1192/bjp.150.5.685

[33] Tyrer SP, Walsh A, Edwards DE, et al. Factors associated with a good response to lithium in aggressive mentally handicapped subjects. Progr Neuro-Psychopharmacol Biol Psych 1984; 8(4-6): 751-55.

[34] Reid AH, Naylor GJ, Kay DSG. A double-blind, placebocontrolled, crossover trial of carbamazepine in overactive severely mentally handicapped patients. Psychol Med 1981; 11: 109-13. http://dx.doi.org/10.1017/S0033291700053320

[35] Lewis $\mathrm{MH}$, Bodfish JW. Clomipramine treatment for selfinjurious behavior of individuals with mental retardation: a double-blind comparison with placebo. Am J Mental Retardation 1996; 100(6): 654-55.

[36] Cohen S, Ihrig K, Lott RS, Kerrick JM. Risperidone for Aggression and Self-Injurious Behavior in Adults with Mental Retardation. J Autism Dev Disord 1998; 28(3): 229-33. http://dx.doi.org/10.1023/A:1026069421988

[37] Durst R, Rubin-Jabotinsky K, Raskin S, Katz G, Zislin J. Risperidone in treating behavioural disturbances of PraderWilli syndrome. Acta Psychiatr Scand 2000; 102: 461-65. http://dx.doi.org/10.1034/j.1600-0447.2000.102006461.x

[38] Lott RS, Kerrick MJ, Cohen SA. Clinical and economic aspects of risperidone treatment in adults with mental retardation and behavioral disturbance. Psychopharmacol Bull 1996; 32: 721-29.

[39] Khan BU. Brief report: risperidone for severely disturbed behavior and tardive dyskinesia in developmentally disabled adults. J Autism Dev Disord 1997; 27: 479-89. http://dx.doi org/10.1023/A:1025813607005

[40] Simon E, Blubaugh KM, Pippidis M. Substituting traditional antipsychotics with risperidone for individuals with mental retardation. Ment Retard 1996; 34: 359-66.

[41] Verhoeven WM. Brief Report: Cyclothymia or Unstable Mood Disorder? A Systematic Treatment Evaluation with Valproic Acid. J Neural Transm 2001; 108(6): 617-27. http://dx.doi.org/10.1007/s007020170039

[42] Bodfish JW, Madison JT. Diagnosis and fluoxetine treatment of compulsive behavior disorder of adults with mental retardation. Am J Ment Retard 1993; 98(3): 360-7.

[43] Troisi A, Vicario E, Nuccetelli F, Ciani N, Pasini A. Effects of fluoxetine on aggressive behavior of adult inpatients with mental retardation and epilepsy. Pharmacopsychiatry 1995; 28(3): 73-6. http://dx.doi.org/10.1055/s-2007-979593

[44] Davanzo PA, Belin TR, Widawski MH, King BH. Paroxetine treatment of aggression and self-injury in persons with mental retardation. Am J Ment Retard 1998; 102(5): 427-37. http://dx.doi.org/10.1352/0895 8017(1998)102<0427:PTOAAS > 2.0.CO;2

[45] La Malfa G, Bertelli M, Conte M. Fluvoxamine and aggression in mental retardation. Psychiatr Serv 2001; 52(8): 1105.

http://dx.doi.org/10.1176/appi.ps.52.8.1105

[46] Natarajan D, Martin AJ, Tesh D. Risperidone therapy in the control of behavioural disturbances in patients with learning disability. Ir J Psychol Med 1997; 14: 69-71.

[47] Ruedrich SL, Swales TP, Rossvanes C, Diana L, Arkadiev V, Lim K. Atypical antipsychotic medication improves aggression, but not self-injurious behaviour, in adults with intellectual disabilities. J Intellect Disabil Res 2008; 52(Pt 2): 132-40.

[48] Cohen S, Fitzgerald B, Okos A, et al. Weight, lipids, glucose, and behavioral measures with ziprasidone treatment in a 
population with mental retardation. J Clin Psychiatry 2003; 64(1): 60-2.

http://dx.doi.org/10.4088/JCP.v64n0112

[49] Buzan RD, Dubovsky SL, Firestone D, et al. Use of clozapine in 10 mentally retarded adults. J Neuropsychiatry 1998; 10: 93-95.

[50] Thalayasingam S, Alexander RT, Singh I. The use of clozapine in adults with intellectual disability. J Intellect Disabil Res 2004; 48(Pt 6): 572-9. http://dx.doi.org/10.1111/j.1365-2788.2004.00626.x

[51] Janowsky DS, Barnhill J, Davis JM. Olanzapine for Self Injurious, Aggressive, and Disruptive Behaviors in Intellectually Disabled Adults: A Retrospective, Open Label, Naturalistic Trial. J Clin Psychiatry 2003; 64: 1258-65. http://dx.doi.org/10.4088/JCP.v64n1018

[52] Ruedrich S, Swales TP, Fossaceca C, et al. Effect of divalproex sodium on aggression and self-injurious behaviour in adults with intellectual disability: a retrospective review. J Intellect Disabil Res 1999; 43: 105-11.

http://dx.doi.org/10.1046/j.1365-2788.1999.00193.x

[53] Janowsky DS, Kraus JE, Barnhill J, Elamir B, Davis JM. Effects of topiramate on aggressive, self-injurious, and disruptive/destructive behaviors in the intellectually disabled: an open-label retrospective study. J Clin Psychopharmacol 2003; 23(5): 500-4.

http://dx.doi.org/10.1097/01.jcp.0000088906.24613.76

[54] Dale PG. Lithium therapy in aggressive mentally subnormal patients. Br J Psychiatry 1980; 137: 469-74. http://dx.doi.org/10.1192/bjp.137.5.469

[55] Spreat S, Behar D, Reneski B, Miazzo P. Lithium carbonate for aggression in mentally retarded persons. Compr Psychiatry 1989; 30(6): 505-11. http://dx.doi.org/10.1016/0010-440X(89)90080-1

[56] Langee HR. Retrospective study of lithium use for institutionalized mentally retarded individuals with behavior disorders. Am J Mental Retardation 1990; 94: 448-52.

[57] Janowsky DS, Shetty M, Barnhill J, Elamir B, Davis JM. Serotonergic antidepressant effects on aggressive, selfinjurious and destructive/disruptive behaviours in intellectually disabled adults: a retrospective, open-label, naturalistic trial. Int J Neuropsychopharmacol 2005; 8(1): 3748.

http://dx.doi.org/10.1017/S146114570400481X

[58] Branford D, Baumik S. Selective serotonin re-uptake inhibitors for the treatment of perseverative and maladaptive behaviours of people with intellectual disability. J Intellect Disabil Res 1998; 42(4): 301-6. http://dx.doi.org/10.1046/j.1365-2788.1998.00144.x

[59] Brahm NC, Farmer KC, Brown RC. Risperidone for the treatment of fecal smearing in a developmentally disabled adult. Am J Health Syst Pharm 2007; 64(4): 382-4. http://dx.doi.org/10.2146/ajhp060176
[60] Kamal M, Kerry M. The use of clozapine in an individual with moderate intellectualdisability, aggressive behavior and resistant psychosis. Ir J Med Psych 1999; 16(1): 32-33.

[61] Goetzl U, Grunberg F, Berkowitz B. Lithium carbonate in the management of hyperactive aggressive behavior of the mentally retarded. Compr Psychiatry 1977; 18(6): 599-606. http://dx.doi.org/10.1016/S0010-440X(97)90013-4

[62] Sovner R, Hurley A. The management of chronic behavior disorders in mentally retarded adults with lithium carbonate. J Nerv Ment Dis 1981; 169(3): 191-5.

http://dx.doi.org/10.1097/00005053-198103000-00007

[63] Mattes JA. Valproic acid for nonaffective aggression in the mentally retarded. J Nerv Ment Dis 1992; 180(9): 601-2. http://dx.doi.org/10.1097/00005053-199209000-00013

[64] Luiselli JK, Blew P, Thibadeau S. Therapeutic effects and long-term efficacy of antidepressant medication for persons with developmental disabilities. Behavioral assessment in two cases of treatment-resistant aggression and self-injury. Behav Modif 2001; 25(1): 62-78.

http://dx.doi.org/10.1177/0145445501251004

[65] Gedye A. Serotonergic treatment for aggression in a Down's syndrome adult showing signs of Alzheimer's disease. J Ment Defic Res 1991; 35(3): 247-58.

[66] O'Neil M, Page N, Adkins WN, Eichelman B. Tryptophantrazodone treatment of aggressive behaviour. Lancet 1986; 2(8511): 859-60.

http://dx.doi.org/10.1016/S0140-6736(86)92890-4

[67] Antonacci DJ, Manuel C, Davis E. Diagnosis and treatment of aggression in individuals with developmental disabilities. Psychiatr Q 2008; 79(3): 225-47. http://dx.doi.org/10.1007/s11126-008-9080-4

[68] Aman MG, Singh NN, Stewart AW, Field CJ. The aberrant behavior checklist: a behavior rating scale for the assessment of treatment effects. Am J Ment Defic 1985; 89(5): 485-91.

[69] Rojahn J, Matson JL, Lott D, Esbensen AJ, Smalls Y. The Behavior Problems Inventory: an instrument for the assessment of self-injury, stereotyped behavior, and aggression/destruction in individuals with developmental disabilities. J Autism Dev Disord 2001; 31(6): 577-88. http://dx.doi.org/10.1023/A:1013299028321

[70] Yudofsky SC, Silver JM, Jackson W, Endicott J, Williams D. The Overt Aggression Scale for the objective rating of verbal and physical aggression. Am J Psych 1986; 143(1): 35-39.

[71] Guy W. ECDEU assessment manual for psycho pharmacology. Rev. Rockville, MD: U.S. National Institute of Health. Psycho-Pharmacol Res Branch 1976; 218-22.

\section{DOI: http://dx.doi.org/10.6000/2292-2598.2013.01.01.5}

(C) 2013 Roy et al.; Licensee Lifescience Global.

This is an open access article licensed under the terms of the Creative Commons Attribution Non-Commercial License (http://creativecommons.org/licenses/by-nc/3.0/) which permits unrestricted, non-commercial use, distribution and reproduction in any medium, provided the work is properly cited. 